\title{
DREAM TEAMS AND THE APOLLO EFFECT
}

\author{
Alex Gershkov \\ alexg@huji.ac.il \\ Paul Schweinzer \\ Alpen-Adria-Universität Klagenfurt, Austria \\ paul.schweinzer@aau.at
}

The Hebrew University of Jerusalem, Israel and University of Surrey, UK

\begin{abstract}
We model leadership selection, competition, and decision making in teams with heterogeneous membership composition. We show that if the choice of leadership in a team is imprecise or noisy — which may arguably be the case if appointment decisions are made by non-expert administrators-then it is not necessarily the case that the best individuals will be selected as team members. On the contrary, and in line with what has been called the "Apollo effect," a "dream team" consisting of unambiguously higher-performing individuals may perform worse in terms of team output than a group composed of lower performers. We characterize the properties of the leadership selection and production processes that lead to the Apollo effect. Finally, we clarify when the opposite effect occurs in which supertalent performs better than comparatively less qualified groups.
\end{abstract}

Keywords: Team composition, leadership, mistakes.

JEL Classification Numbers: C70, D70, J80.

We thank Mike Borns, Philipp Hungerländer, Alberto Versperoni, and seminar participants at the University of Vienna for helpful comments and discussions. This project was supported by funds of the Oesterreichische Nationalbank (Austrian Central Bank, Anniversary Fund, project number: 17663).

Copyright (C) Alex Gershkov, Paul Schweinzer / 6(1), 2021, 113-148. 


\section{INTRODUCTION}

7 HE "Apollo Syndrome" is a phenomenon first described and popularized 1 in the management literature by Belbin (1981). It describes situations in which teams of highly capable individuals, collectively, perform badly. The phenomenon is named after the mission teams in NASA's Apollo space program and refers to situations in which one team is composed of unambiguously more capable individuals than the teams with which it is compared. Contrary to intuition, in the experiments Belbin conducted in the sixties at what is now Henley Business School, the Apollo teams often finished near the bottom among the competing teams. ${ }^{1}$ One of the reasons Belbin gives for the Apollo teams' failure is that Apollo team members "spent a large part of their time engaged in abortive debate, trying to persuade the other members of the team to adopt their own particular, well-stated point of view. No one seemed to convert another or be converted. However, each seemed to have a flair for spotting the weak points of the other's argument. [...] Altogether, the Apollo company of supposed supertalent proved an astonishing disappointment" (Belbin, 1981, p. 15$).^{2}$

For our main result, we model a team production problem in which an executive or administrator (either a principal or the team itself) appoints a single leader and subsequently all team members produce joint output by exerting individual efforts. We assume that the administrator is more likely to select a "wrong" or suboptimal leader if the skills of the candidates are similar. The model represents the administrator's selection capabilities through a symmetric black-box function (for which we supply micro-justifications) that with some probability selects individuals for leadership positions on the basis of their innate leadership skills, which are unknown to the executive. The

1 "Of 25 companies that we constructed according to our Apollo design, only three became the winning team. The favourite finishing position out of eight was sixth (six times), followed by fourth (four times)" (Belbin, 1981, p. 20). The performance data of the remaining Apollo teams is not available. If we allocate the remaining 12 teams with equal probability to each remaining rank, the resulting hypothetical expected Apollo rank is 4.6.

2 The general observation itself is not novel. For instance, it finds expression in the description of the sinking of the Mary Rose: "it chanced unto this gentleman, as the common proverb is, - the more cooks the worse potage, he had in his ship a hundred marines, the worst of them being able to be a master in the best ship within the realm; and these so maligned and disdained one the other, that refusing to do that which they should do, were careless to do that which was most needful and necessary, and so contending in envy, perished in forwardness" (Hooker, J., The Life of Sir Peter Carew, 1575). 
higher the skill differences, the easier it is to find the better team leader. We show that in this environment the Apollo effect-which we define as a team of highly skilled individuals being outperformed by a team consisting entirely of lower-qualified members-is generally inescapable and arises from any noisy selection process.

The process of the selection of candidates for leadership roles is as follows. The (human resources) executive or administrator charged with assigning tasks to workers and managers is not an expert in the production processes for which the appointments under consideration are made. She collects information on the performance of the individuals according to some standardized management selection protocol. Although she may perform her job admirably, she occasionally makes the wrong leadership assignment.

The narrative offered in this Introduction explains the Apollo effect based on competition for leadership. This need not be taken literally, however. Any potential for conflicting opinions, differential styles of conducting business, management philosophies, etc, can be similarly thought of as the basis for the frictions that are modeled through our black-box assignment function. ${ }^{3}$ In section 4 we define and describe the properties of a task-matching model in which the single-leadership feature is replaced by a function that matches workers to differentially productive tasks. In this extension of the model, the assignment function models the potential for mistakenly assigning the wrong worker to a given task. Although the Apollo effect is less prevalent in this environment than in the leadership game, we show that there are always skill profiles of workers for which the Apollo effect can arise for suitably noisy taskselection technologies. While we assume in the main body of our analysis that workers know each other's skills, we show that the Apollo effect persists under incomplete skill information among workers. Finally, we show that the Apollo effect exists regardless of the introduction of a profit-maximizing principal into the pure team environment.

The rest of the paper is organized as follows. After a short overview of the related literature we define our model in Section 2. Section 3 presents and illustrates our main result, the ubiquity of the Apollo effect. Section 4 discusses several extensions, alternative interpretations, and the robustness of the main model. In the concluding Section 5 we discuss a further set of potential applications and extensions. Proofs of all the results and details of

3 A simple "lost production complementarities" explanation of the Apollo effect which is similar to Belbin's own story is illustrated in example 4 . 
some of the derivations can be found in the Appendix.

\section{Literature}

Belbin (1981) introduces a "team role" theory designed to enhance team composition based on a series of business school training games. ${ }^{4}$ The Apollo syndrome is described as an effect of team composition and as such it is distinct from the "Ringelmann-type" free-riding (or social loafing) due to moral hazard in teams (Gershkov et al., 2016).

Cyert \& March (1963), Marschak \& Radner (1972), and Holmström (1977) generated a rich literature on the economics of organizations. We are unaware, however, of any attempt in the theoretical literature to introduce systematic errors into (team) decision-making processes and analyze their effect on team performance and team composition. There are accounts of cognitive biases and heuristics in the management literature (e.g., Schwenk, 1984; Gary, 1998), psychology (e.g., Kahneman, 2003; Gigerenzer \& Gaissmaier, 2011), sports (e.g., Lombardi et al., 2014), and administrative science (e.g., Tetlock, 2000), but we know of no directly related explorations in economics.

The existing economic literature on team composition problems consists of only a handful of papers. Chade \& Eeckhout (2020) analyze problems of team composition when teams compete subsequent to the matching stage. ${ }^{5}$ Their matching setup results in a model in which the externalities that affect sorting patterns differ substantially from those of the standard case. ${ }^{6}$ Eliaz \& Wu (2018) use an all-pay auction to model the competition between two teams. In their setup, the competing teams may differ in size and have

4 For recent management surveys on team composition and pointers to empirical work, see, for example, Aritzeta et al. (2007) or Mathieu et al. (2013). There is a topical link to the literatures on collective intelligence in organizations (Woolley et al., 2015) and on swarm intelligence/stupidity (Kremer et al., 2014).

5 In their motivation, Chade \& Eeckhout (2020) ask whether or not a single "superstar" team would have been able to confirm the existence of the Higgs boson quicker than the competing ATLAS and CMS teams at CERN's Large Hadron Collider.

6 In the settings we analyze, the optimal allocation is usually given by assortative matching, that is, the more talented team member should be assigned the leadership position or the higher productivity task. However, as the administrator (or organization) assigns leadership positions based on imprecise skill information, this results in a noisy allocation (for bounds on efficiency in the case of coarse matching see McAfee, 2002). The main departure from this literature is that, in our analysis, the matching procedure is taken into account in the specified compensation scheme. 
incomplete information on the prize the opposing team receives as a groupspecific public good. They explore the interplay of the effort aggregation (or team production) function's curvature with individual incentives and analyze endogenous team formation from the angles of aggregation and differing team size. Palomino \& Sákovics (2004) discuss a model of revenue sharing when sports teams competitively bid to attract talent. They find that the organization of the league(s) is key to the optimal design of remuneration schemes and the resulting availability of talent. In a paper on board composition, Hermalin \& Weisbach (1988) discuss how firm performance and CEO turnover determine the choice of directors. None of these papers develops the core issue of our paper, namely, leadership selection under assignment errors.

The endogenous emergence of team leadership is modeled explicitly in several recent papers. In Kobayashi \& Suehiro (2005), each of two players obtains imperfect, private signals on team productivity. The individual incentives to lead by example (as in Hermalin, 1998) give rise to a coordination problem. Andreoni (2006) analyzes a public goods provision game in which a team can learn the project type by individually expending a small amount of goods and the investing "leader" faces free-riding incentives. Huck \& Rey-Biel (2006) analyze teams of asymmetrically productive agents biased towards conformism. They find that the less productive of two equally biased agents should lead. By contrast, our paper does not model a particular leadership game but employs a black-box assignment function yielding selection probabilities based on idiosyncratic skills that should, in principle, be compatible with a large set of selection procedures.

Finally, there are many issues in the organizational design literature that are touched on in this paper, such as the concept of leadership (Hermalin, 1998; Lazear, 2012), battles for control (Rajan \& Zingales, 2000), sequentiality of production (Winter, 2006), transparency of effort (Bag \& Pepito, 2012), and repetition (Che \& Yoo, 2001). For other aspects of organizational theory see the excellent recent overviews by Bolton et al. (2010); Hermalin (2012); Waldman (2012); Garicano \& Van Zandt (2012).

\section{THE MODEL}

There is a team consisting of two members $\{1,2\}$. Each team member is supposed to exert unobservable effort that contributes to joint output. In addition, each team member $i \in\{1,2\}$ is attributed with managerial or leadership skill 
$\theta_{i} \in \mathbb{R}_{+}$. The team's output depends on the assigned leader and on the efforts of all team members. ${ }^{7}$ Denote by $y\left(\theta_{i}, e_{1}, e_{2}\right)$ the team output when agent $i \in\{1,2\}$ is assigned to lead the team, agent 1 exerts effort $e_{1}$ and agent 2 exerts effort $e_{2}$. The cost of exerting effort $e_{i}$ is the same for both agents, $c\left(e_{i}\right)$, with $c^{\prime}(0)>0, c^{\prime}>0$, and $c^{\prime \prime}>0$. The effect of the agents' effort exertion on output is symmetric, that is, for any $\theta_{i}, e_{1}$ and $e_{2}$ the team generates

$$
y\left(\theta_{i}, e_{1}, e_{2}\right)=y\left(\theta_{i}, e_{2}, e_{1}\right) .
$$

We assume that $y$ is differentiable with

$$
y_{1}=\frac{\partial y}{\partial \theta_{i}}>0, y_{j+1}=\frac{\partial y}{\partial e_{j}}>0, y_{j+1, j+1}=\frac{\partial^{2} y}{\partial e_{j}^{2}}<0, y_{j+1,1}=\frac{\partial^{2} y}{\partial e_{j} \partial \theta_{i}}>0
$$

for any $j \in\{1,2\}$. The time structure of the modeled events is as follows. At the first stage of the interaction, one of the agents is appointed the team leader. At the second stage, the agents exert uncontractible efforts after observing the chosen leader and his leadership skill. ${ }^{8}$ The resulting output is divided equally between the team members. ${ }^{9}$ Monotonicity of output $y$ with respect to the leader's skill attribute implies that it is optimal to choose the agent with the highest leadership skills as a team leader.

The main premise of the paper, however, is that selecting a team leader (or decision making in general) is a complex process that sometimes involves mistakes. ${ }^{10}$ More precisely, we denote by $f\left(\theta_{i}, \theta_{j}\right)$ the probability that agent $i$ is appointed to the leadership position when $i$ 's leadership skills are represented by parameter $\theta_{i}$, while the other team member's skill is $\theta_{j}$. With probability

7 The leadership position creates a (sufficiently high) private and non-monetary benefit to the appointed leader, which renders the trivial (and potentially first-best) solution of "selling the project to the manager" infeasible. For empirical justifications of such benefits including "self-dealing," see, for instance, Tirole (2006, p. 17).

8 Similarly to the sequential game outlined above, the Apollo effect can be shown to exist in a simultaneous production version of the model in which all players choose their respective strategies at the same time.

9 The paper's results hold regardless of the chosen output division rule. In particular, it is unimportant for the occurrence of the Apollo effect whether incentives are provided to exert (constrained) efficient efforts or not (Gershkov et al., 2016).

${ }^{10}$ As detailed in our assumptions (3) and (4) below, in order for the Apollo effect to arise, the function $f\left(\theta_{i}, \theta_{j}\right)$ must decrease sufficiently in $\theta_{j}$ : a "simple" constant probability of making mistakes is not sufficient. 
$1-f\left(\theta_{i}, \theta_{j}\right)$ player $j$ is assigned the leadership position. We assume that the assignment function is symmetric:

$$
f\left(\theta_{i}, \theta_{j}\right)=1-f\left(\theta_{j}, \theta_{i}\right)
$$

responsive:

$$
\frac{\partial f\left(\theta_{i}, \theta_{j}\right)}{\partial \theta_{i}}>0
$$

and satisfies appropriate probability limit behavior, in particular $f(0, \hat{\theta})=0$ for $^{11} \hat{\theta}>0$.

In the Introduction, we informally motivate how this function $f$ may arise from some management selection processes. We now give two more formal micro-justifications for the main properties of the black-box function we use throughout the paper. In the first formalization, we think of the appointing executive as having access to a test that is potentially capable of ranking the candidates: if one candidate is below and the other candidate is above the test location, then the test returns the ranking. If both candidates are below or above the test location, then one candidate is picked at random. Being less than perfectly well informed, however, the executive can choose the location of the test only probabilistically. Assume that the test realizes at threshold $\hat{\theta}$ with positive density $t(\hat{\theta})$. Then the probability of player 1 with skill $\theta_{1}$ being chosen under this test is

$$
\frac{1}{2}\left[\int_{0}^{\min \left(\theta_{1}, \theta_{2}\right)} t(\hat{\theta}) d \hat{\theta}+\int_{\max \left(\theta_{1}, \theta_{2}\right)}^{1} t(\hat{\theta}) d \hat{\theta}\right]+\mathbf{1}_{\left\{\theta_{1} \geq \theta_{2}\right\}} \int_{\min \left(\theta_{1}, \theta_{2}\right)}^{\max \left(\theta_{1}, \theta_{2}\right)} t(\hat{\theta}) d \hat{\theta} .
$$

The derivatives for any realization of $\theta_{1}>\theta_{2}$ are as required by our assumptions.

Our second micro-foundation is based on the idea that the administrator can make noisy observations of the two agents' types $\theta_{i}+\varepsilon_{i}$ and knows only that $\varepsilon_{i}$ is distributed independently and identically according to any continuous distribution $H$ (for a complete model development, see Lazear \& Rosen, 1981). The administrator then bases a decision on her noisy observation of leadership abilities. In this environment, the probability that agent 1 will be appointed is

$$
\operatorname{Pr}\left(\theta_{1}+\varepsilon_{1}>\theta_{2}+\varepsilon_{2}\right)=\operatorname{Pr}\left(\varepsilon_{2}-\varepsilon_{1}<\theta_{1}-\theta_{2}\right) \equiv P,
$$

where the difference between the two independently distributed random variables is itself a continuously distributed random variable. The derivatives of this assignment probability $P$ satisfy the required properties of $f\left(\theta_{1}, \theta_{2}\right)$.

11 The implied discontinuity at $f(0,0)$ does not play a role in our analysis. 


\section{THE MAIN RESULTS}

This section presents the principal finding of this paper, the ubiquity of the Apollo effect. Before we start the formal analysis we would like to point out that the first-best efficient selection in which the better-qualified player is always appointed the team leader by an uninformed administrator is generally unattainable in the specified game based on selection capabilities $f$. We start the discussion by means of a simple illustrative example of the main idea.

Example 1: In the following comparative static arguments we distinguish between two teams $j \in\{\mathrm{A}, \mathrm{B}\}$ and typically assume that team members' abilities are ranked $\theta_{1}^{A} \geq \theta_{1}^{B}$ and $\theta_{2}^{A} \geq \theta_{2}^{B}$, where team A consists of unambiguously higher-ability players than team $B$. For leadership selection, an administrator employs a black-box function based on ability ratios according to which the probability of player $i \in\{1,2\}$ being selected as leader is ${ }^{12}$

$$
f\left(\theta_{i}, \theta_{j}\right)=\frac{\theta_{i}^{r}}{\theta_{1}^{r}+\theta_{2}^{r}}, r>0 .
$$

If player $i \in\{1,2\}$ is selected as team $j$ 's leader $(j \in\{A, B\})$, then $\hat{\theta}=\theta_{i}^{j}$ and the team generates simple linear output

$$
y\left(\hat{\theta}, e_{1}, e_{2}\right)=\hat{\theta}\left(e_{1}+e_{2}\right) .
$$

As either player 1's or player 2's ability is employed exclusively for leadership, we refer to this case as "exclusive" management or production. ${ }^{13}$ Following the time structure outlined above, workers know whether or not they are assigned leadership roles before exerting effort, i.e., any mistakes are made during a first leadership-assignment stage while unobservable efforts are exerted by perfectly informed agents at a second stage. More specifically, player $i$ 's stage2 objective, given that the player with type $\hat{\theta}$ is chosen as leader and output is shared equally, is

$$
\max _{e_{i}} \frac{y\left(\hat{\theta}, e_{i}, e_{j}\right)}{2}-c\left(e_{i}\right) .
$$

12 In different environments similar functions have been called "logistic" or "sigmoid" functions. The contest literature refers to a variant of (7) as "ratio," "power," or "Tullock" contest success function (Jia et al., 2013). Note that—as there are no strategies involved at this stage-our use of this function for leadership selection is purely descriptive and does not constitute a game.

${ }^{13}$ We later extend our model to task-matching in order to also capture shared production aspects in teams with complementary skills where individuals are matched to tasks. 
Assuming quadratic effort $\operatorname{costs} c(e)=e^{2}$, symmetric equilibrium efforts are simply

$$
e_{1}(\hat{\theta})=e_{2}(\hat{\theta})=\hat{\theta} / 2
$$

At the leadership selection stage, the administrator selects either player 1 with probability $f\left(\theta_{1}, \theta_{2}\right)$ or player 2 with probability $1-f\left(\theta_{1}, \theta_{2}\right)$ as the team leader. Hence, the first-stage expected equilibrium team output is

$$
\begin{aligned}
Y\left(\theta_{1}, \theta_{2}\right) & =f\left(\theta_{1}, \theta_{2}\right) y\left(\theta_{1}, e\left(\theta_{1}\right), e\left(\theta_{1}\right)\right)+\left(1-f\left(\theta_{1}, \theta_{2}\right)\right) y\left(\theta_{2}, e\left(\theta_{2}\right), e\left(\theta_{2}\right)\right) \\
& =\theta_{2}^{2}+f\left(\theta_{1}, \theta_{2}\right)\left(\theta_{1}^{2}-\theta_{2}^{2}\right) \\
& =\frac{\theta_{1}^{r+2}+\theta_{2}^{r+2}}{\theta_{1}^{r}+\theta_{2}^{r}} .
\end{aligned}
$$

We now implicitly define an "isoquant" function $\theta_{2}\left(\bar{y}, \theta_{1}\right)$, which determines the type $\theta_{2}$ that achieves the constant output level $\bar{y}$ for some type $\theta_{1}$. An example is shown in Figure 1: low precision $r=.25$ is shown on the left, moderate precision $r=2$ in the middle, and high precision $r=15$ on the right. ${ }^{14}$ We restrict attention (without loss of generality) to $\theta_{1} \geq \theta_{2}$, and so only the subset under the diagonal is relevant in the figure. Team compositions "under the isoquant," i.e., to the left of the isoquant $\theta_{2}\left(\bar{y}, \theta_{1}\right)$, produce lower output than $\bar{y}$. Skill pairs "above the isoquant," i.e., to the right of isoquant $\theta_{2}\left(\bar{y}, \theta_{1}\right)$, produce higher output than $\bar{y}$. The Apollo effect arises here because, for any point $\left(\hat{\theta}_{1}, \hat{\theta}_{2}\right)$ on a positively sloped part of an isoquant, we can find a point $\left(\theta_{1}>\hat{\theta}_{1}, \theta_{2}>\hat{\theta}_{2}\right)$ under this isoquant (close to where it is vertical), such that $y\left(\hat{\theta}_{1}, \hat{\theta}_{2}\right)>y\left(\theta_{1}, \theta_{2}\right)$. Note that one would not expect a positive slope of the isoquants in Figure 1 without the defined possibility of making mistakes in leadership assignment. In this example, the Apollo effect crops up for all selection precisions, provided that the spread $\theta_{1}-\theta_{2}$ is sufficiently high. $\triangleleft$

One may, however, ask how pervasive the occurrence of the Apollo effect is in the above example. In order to answer this question, we start the formal argument by defining the Apollo effect in a general production environment with two teams.

14 We refer to the exponent $r$ in (7) as the "selection precision" of player 1 because it parameterizes the derivative of the assignment function with respect to $\theta_{1}$. The comparison case of no mistakes is obtained for $r \rightarrow \infty$, i.e., $f\left(\theta_{1}, \theta_{2}\right)=1$ iff $\theta_{1} \geq \theta_{2}$. In this case, the level sets in the right panel of Figure 1 become a perfectly rectangular map. By contrast, if $r=0$, we have $f\left(\theta_{1}, \theta_{2}\right)=1 / 2$ for any $\theta_{1}$ and $\theta_{2}$. 

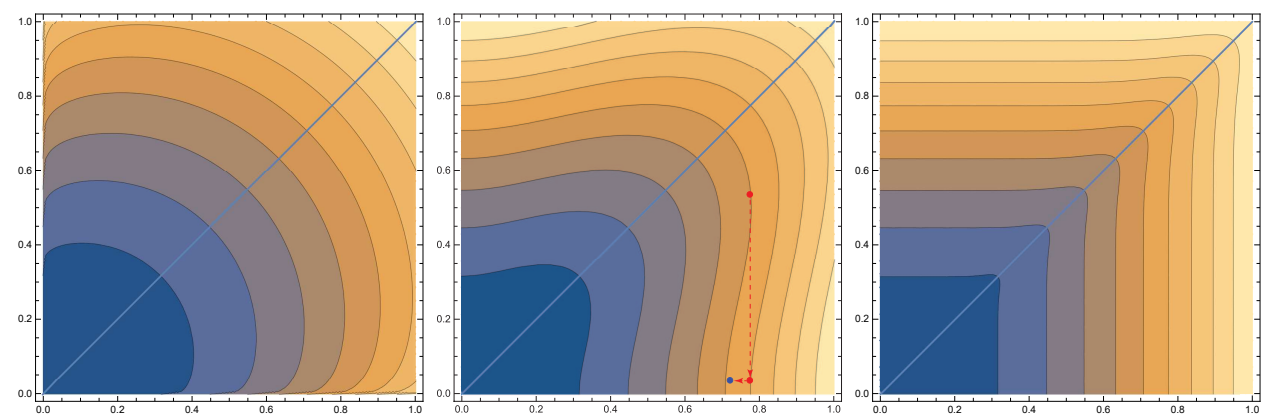

Figure 1: "Isoquant" expected team output level sets with $\theta_{1}$ on the horizontal and $\theta_{2}$ on the vertical axis for $r=.25$ on the left, $r=2$ in the middle, and $r=15$ on the right.

Definition 1. The environment expresses the Apollo effect, if there exist two teams $\{A, B\}$ with leadership skills $\left(\theta_{1}^{A}, \theta_{2}^{A}\right)>>\left(\theta_{1}^{B}, \theta_{2}^{B}\right)$ with $y^{A}<y^{B}$, where $y^{A}$ is the equilibrium output of team $A$ and $y^{B}$ is that of team $B$.

Without loss of generality, we assume that $\theta_{1} \geq \theta_{2}$. Observing the appointed leader of type $\hat{\theta}$ and assuming equal sharing of output, team member $i$ maximizes effort stage utility

$$
\max _{e_{i}} \frac{y\left(\hat{\theta}, e_{1}, e_{2}\right)}{2}-c\left(e_{i}\right)
$$

Taking the derivative with respect to $e_{i}$, we define symmetric equilibrium effort $e^{*}=e_{1}=e_{2}$ as

$$
y_{i+1}\left(\hat{\theta}, e_{i}, e_{j}\right)-2 c^{\prime}\left(e_{i}\right)=0,
$$

where subscripts on functions denote derivatives. The assumed curvature of the output and cost functions guarantee that $e^{*}(\hat{\theta})$ is non-decreasing. We substitute these equilibrium efforts into output that determines equilibrium team output as

$$
\begin{aligned}
Y\left(\theta_{1}, \theta_{2}\right)= & f\left(\theta_{1}, \theta_{2}\right) y\left(\theta_{1}, e^{*}\left(\theta_{1}\right), e^{*}\left(\theta_{1}\right)\right) \\
& +\left(1-f\left(\theta_{1}, \theta_{2}\right)\right) y\left(\theta_{2}, e^{*}\left(\theta_{2}\right), e^{*}\left(\theta_{2}\right)\right) .
\end{aligned}
$$

It turns out that an analytically convenient way to demonstrate that the Apollo effect exists is to show that there exists a skill combination $\left(\theta_{1}, \theta_{2}\right)$ such that 
$y\left(\theta_{1}, \theta_{2}\right)$ has a positive gradient, i.e., there exist $\left(\eta_{1}, \eta_{2}\right)>>0$ such that

$$
\frac{\partial Y\left(\theta_{1}, \theta_{2}\right)}{\partial \theta_{1}} \eta_{1}+\frac{\partial Y\left(\theta_{1}, \theta_{2}\right)}{\partial \theta_{2}} \eta_{2}<0
$$

Our main claim is that there exists a team endowed with skills $\theta^{A}$ for which the equilibrium team output shrinks if both types are increased infinitesimally.

Lemma 2. The Apollo effect arises if and only if

$$
-\frac{f_{2}\left(\theta_{1}, \theta_{2}\right)}{1-f\left(\theta_{1}, \theta_{2}\right)}>\frac{e^{*}\left(\theta_{2}\right) 2 y_{e}\left(\theta_{2}, e^{*}\left(\theta_{2}\right), e^{*}\left(\theta_{2}\right)\right)+y_{1}\left(\theta_{2}, e^{*}\left(\theta_{2}\right), e^{*}\left(\theta_{2}\right)\right)}{y\left(\theta_{1}, e^{*}\left(\theta_{1}\right), e^{*}\left(\theta_{1}\right)\right)-y\left(\theta_{2}, e^{*}\left(\theta_{2}\right), e^{*}\left(\theta_{2}\right)\right)} .
$$

The lemma allows us to specify when the Apollo effect is plausible. It shows that increasing the difference between the team members increases the chance of observing the Apollo effect (if $y\left(\theta_{1}, e^{*}\left(\theta_{1}\right), e^{*}\left(\theta_{1}\right)\right)$ $y\left(\theta_{2}, e^{*}\left(\theta_{2}\right), e^{*}\left(\theta_{2}\right)\right)$ is high, $f\left(\theta_{1}, \theta_{2}\right)$ is high and hence it is easier to satisfy the condition of the last Lemma). Moreover, the probability of misallocation must be responsive to the skills, that is, $f_{2}\left(\theta_{1}, \theta_{2}\right)$ must be substantially low (and negative).

An immediate implication of the lemma and its proof is that while it is always beneficial for the best team member to improve her leadership skills, this is certainly not the case for the lower-qualified team member. We proceed to state a general property of exclusive production.

Lemma 3. For exclusive production $y(\theta, e(\theta), e(\theta))$ and any $\hat{\theta}>0$, we have

$$
\begin{aligned}
& f(\hat{\theta}, \hat{\theta}) y(\hat{\theta}, e(\hat{\theta}), e(\hat{\theta}))+(1-f(\hat{\theta}, \hat{\theta})) y(\hat{\theta}, e(\hat{\theta}), e(\hat{\theta})) \\
& \quad=f(\hat{\theta}, 0) y(\hat{\theta}, e(\hat{\theta}), e(\hat{\theta}))+(1-f(\hat{\theta}, 0)) y\left(0, e(0), e_{2}(0)\right) .
\end{aligned}
$$

Therefore, for any $\hat{\theta}$, the points $(\hat{\theta}, \hat{\theta})$ and $(\hat{\theta}, 0)$ belong to the same isoquant. Note that for symmetric functions $f$, the isoquants' slope at $\theta_{1}=\theta_{2}$ must be -1 at the diagonal of our level sets. Together, these observations imply the following general result.

Proposition 1. The Apollo effect arises under an exclusive leadership assignment for every feasible continuous function $f$.

This result shows that the only case in which the Apollo effect cannot arise is if the defined possibility of making mistakes in leadership selection is 
entirely absent. For concave production technology, and any conceivable not infinitely accurate continuous leadership selection technology $f$, there will be skill profiles that give rise to the Apollo effect, i.e., where unambiguously better-qualified teams must be expected to produce lower output than a set of "underdogs." Before we proceed to explore the implications of our main result through a series of applications and direct extensions in the form of remarks we should point out that this result is an implication of the introduced possibility for errors in the leadership selection process. This will not be the case in the "task-matching" generalization of the following section.

Remark 4 (Dispersion \& conflict). Why do Apollo teams have more problems in appointing the right leader than less-qualified teams? "A possible answer lies in the very pressures that our educational system and culture exert on clever people. Those who at school are 'top of the class,' or who have it within their reach, are continually being judged in terms of their scholastic preeminence. To come second is to fail. Beating the next person is the name of the game. Difficult problems excite the greatest rivalry and so destroy the bonds of mutual co-operation and complementary functioning upon which the success of a team ultimately depends. In other words, overconcentration on coming top of the class provides an unconscious training in anti-teamwork." Belbin (1981, p. 18)

In our model the probability of being appointed as leader is a function of the skill-dispersion of the team: more dispersed teams have fewer problems in selecting the better leader. The Apollo-effect arises if and only if the gain in expected output due to a more dispersed non-Apollo team (and therefore higher probability of selecting the right type as leader) can more than compensate for the potential loss of erroneously selecting the wrong leader in the better Apollo team. The above quotation suggests that there may be good reasons to expect this higher probability of agreement in lower-quality teams.

We reiterate and emphasize that we do not claim that less talented teams make better decisions in choosing a leader. However, it is the case that, in a more dispersed team, both an outsider's task of identifying the better qualified individual is easier and team members themselves will be less eager to fight for leadership if the difference in abilities is stark.

Remark 5 (Labor market). The environment of Proposition 1 can be used to study the effect of imprecise leadership selection on the optimal assignment 
of agents to several teams. We keep the same informational assumptions as in the rest of this section but are here only interested in characterizing the optimal team composition, rather than a game capable of bringing it about. In particular, we ask which agent types from the ordered set $\theta_{1}>\theta_{2}>\cdots>\theta_{n}$, $n \geq 3$ optimally self-select and for what team structure.

We assume that the firm wishes to create $k<n / 2$ teams of two agents each. Subsequent to the creation of the teams, a leader will be chosen in each team following the procedure described above. How should the hiring and team creation process take the later noisy leadership selection into account? To answer this question, we have to identify the optimal hiring and matching strategies assuming that the types are observable at this stage. This illustrates which types should be targeted and the information that needs to be collected on candidates.

Absent the possibility of making mistakes in subsequent leadership selection, an optimal matching is to form $k$ teams with team $j$ led by agent $\theta_{2 j-1}$, i.e., one of the $k$ agents with the highest leadership ability with any second agent chosen from the lower half of the types. If the lower-skill partners' types have an arbitrarily small output contribution, then the lowest type $(s)\left(\theta_{2 k+1}, \ldots, \theta_{n}\right)$ will never be employed. ${ }^{15}$ Therefore, it is important to identify and exclude the lowest ability types. Yet, if leadership assignment is imprecise, an implication of the Apollo effect is that a set of workers strictly better qualified than these "worst" types will be optimally excluded.

Consider, for example, the ordered set of $n=5$ agent types $\theta_{i}=(n-i) /(n-1)$ with identical, linear production $y\left(\theta, e_{1}, e_{2}\right)=\theta\left(e_{1}+e_{2}\right)$, quadratic costs $c(e)=e^{2} / 2$, and ratio assignment $f(\theta)=\theta_{i}^{r} /\left(\theta_{i}^{r}+\theta_{j}^{r}\right), r>0$. Assume that the organization needs two teams and hence seeks to exclude one agent. For $r \geq 1$ it is optimal to exclude the agent with median ability $\theta_{3}$. The intuition of "dropping the middle" types for sufficiently precise assignment $f$ can be generalized and has implications for the labor market: firms demand the right types, and not necessarily the highest available types. In the example, given a sufficient precision of $f$, the middle types are left unemployed whereas the lowest type $\theta_{n}$ is employed in all optimal matchings!

Remark 6 (Project selection). Consider a manager's choice between two

15 This positive influence can be made precise and formalized by an infinitesimally small positive multiplier $t_{l}$, as discussed in the task-matching environment of Section 4.1. In general, such a task-matching construction gives qualitatively similar results to exclusive production only for intermediate precisions of the assignment function $f$. 
projects of unknown quality $\theta_{1}, \theta_{2}$, guided by the imperfect selection technology $f\left(\theta_{1}, \theta_{2}\right)$. In this application, project output $y\left(\theta_{i}, K, L\right)$ is increasing in $\theta_{i}$, satisfies the equivalents of Assumptions (1) and (2), and the symmetric factors $K$ and $L$ are chosen by strategic project employees who privately observe quality $\theta_{i}$. Proposition 1 shows that there are situations in which improving both individual projects to $\theta_{1}^{\prime}>\theta_{1}$ and $\theta_{2}^{\prime}>\theta_{2}$ actually decreases the firm's expected revenue relative to the original, unambiguously worse project environment.

Remark 7 (Larger teams). Whereas our other results are stated for assignment functions defining selection probabilities for just two players, we now analyze the consequences of increasing the team size. ${ }^{16}$

For example, consider an n-player version of our model governed by the usual linear production $y\left(\theta, e_{1}, \ldots, e_{n}\right)=\theta\left(e_{1}+\cdots+e_{n}\right)$ and quadratic efforts cost $c(e)=e^{2} / 2$. We adopt a ratio-assignment function that gives the probability of (the highest-type) player 1 being selected as

$$
f\left(\theta_{1}, \ldots, \theta_{n}\right)=\frac{\theta_{1}^{r}}{\theta_{1}^{r}+\cdots+\theta_{n}^{r}}, r>0 .
$$

Provided that all team members share output equally, this results in typecontingent equilibrium efforts of $e=\theta / n$, whereas a benevolent planner would dictate the efficient $e^{*}=\theta$. The Apollo effect also arises in this example as in the two-agent case.

\section{FURTHER RESULTS}

\subsection{Task Matching}

The main result of this paper rests on an interpretation of conflict (for leadership) to explain the Apollo effect since every team member's management skills enter the production process exclusively. Only one of the team members is appointed the leader and the rest's leadership skills are completely discarded.

16 Amazon's Jeff Bezos is reported to employ a "two pizza rule": if a team cannot be fed by two pizzas, then that team is too large. The idea is that having more people work together is less efficient, i.e., team output decreases beyond the optimal size. This is the case in Shellenbarger (2016) who argues that participants tend to feel less accountable in crowded meetings and doubt that any contribution they make will be rewarded, and hence reduce effort. 
Deviating from this interpretation, we now assume that the production technology requires that all workers be matched to their "correct" tasks and therefore all individuals' skills enter production. ${ }^{17}$ That is, we consider an environment in which the organization or its executives must assign team members to different tasks and, after the assignment, the agents apply their skills and exert effort on the allocated tasks. However, this assignment may involve mistakes or misallocations of agents to tasks. We employ the following output function

$$
y\left(\theta_{i}, \theta_{j}, e_{i}, e_{j}\right)=y^{h}\left(\theta_{i}, e_{i}\right)+y^{l}\left(\theta_{j}, e_{j}\right)
$$

where both $y^{h}(\theta, e)$ and $y^{l}(\theta, e)$ are weakly concave and increasing in both arguments. That is, each worker is matched either with task $h$ or with task $l$. Each worker uses "leadership" skills and exerts effort in executing the allocated task. Function $f$ chooses the assignment of workers to tasks. Otherwise, the model is the same as in the previous section. Without loss of generality, we assume that $\theta_{1} \geq \theta_{2}$. We assume that for any $e \geq 0$

$$
y_{1}^{h}(\theta, e)>y_{1}^{l}(\theta, e)>0 .
$$

Therefore, the efficient assignment is that higher-ability agent 1 is assigned task $h$, while agent 2 is assigned task $l$. Given an allocation, the agents will exert effort, as dictated by first-order conditions $\left(e_{i}^{h}\left(\theta_{i}\right), e_{j}^{l}\left(\theta_{j}\right)\right)$ :

$$
y_{2}^{h}\left(\theta_{i}, e_{i}\right)=2 c^{\prime}\left(e_{i}\right), y_{2}^{l}\left(\theta_{j}, e_{j}\right)=2 c^{\prime}\left(e_{j}\right) .
$$

Assuming, in addition to (19), that

$y_{2}^{h}(\theta, e)>y_{2}^{l}(\theta, e)>0, y_{12}^{h}(\theta, e)>y_{12}^{l}(\theta, e)>0$ and $\left.0>y_{22}^{h}(\theta, e)>y_{22}^{l}((\theta)) e,\right)$

implies that equilibrium effort in both tasks is increasing in type and that both $e^{h}(\theta)>e^{l}(\theta)>0$ and $e^{h \prime}(\theta)>e^{l \prime}(\theta)>0$. At the selection stage, the expected team output under task matching is

$$
Y\left(\theta_{i}, \theta_{j}\right)=f\left(\theta_{i}, \theta_{j}\right) z\left(\theta_{i}, \theta_{j}\right)+\left(1-f\left(\theta_{i}, \theta_{j}\right)\right) z\left(\theta_{j}, \theta_{i}\right),
$$

${ }_{17}$ Referring back to our motivational example of the NASA Apollo missions, the Apollo team members were selected to fulfill distinct roles. The Apollo 11 team, for instance, consisted of mission commander Neil Armstrong, command module pilot Michael Collins, and lunar module pilot Edwin Aldrin. Hence, team performance depended on each member of the crew being selected for and performing a very specific task. 
where we assume that $z\left(\theta_{i}, \theta_{j}\right)$ is the equilibrium output if agent $i$ is assigned to task $h$ and agent $j$ is assigned to task $l$, i.e.,

$$
z\left(\theta_{i}, \theta_{j}\right)=y\left(\theta_{i}, \theta_{j}, e_{i}^{h}\left(\theta_{i}\right), e_{j}^{l}\left(\theta_{j}\right)\right) .
$$

Our assumptions above imply that $z\left(\theta_{1}, \theta_{2}\right)>z\left(\theta_{2}, \theta_{1}\right)$. We introduce our result by means of a simple example.

Example 2: We assume that team output is created by the simple production function

$$
y\left(\theta_{i}, \theta_{j}, e_{i}, e_{j}\right)=t_{h} \theta_{i} e_{i}+t_{l} \theta_{j} e_{j}, \text { with } t_{h} \geq t_{l} .
$$

Similarly to the previous example, we assume that costs are quadratic, $c(e)=$ $e^{2}$, and that the allocation technology is

$$
f\left(\theta_{i}, \theta_{j}\right)=\frac{\theta_{i}^{r}}{\theta_{1}^{r}+\theta_{2}^{r}}, r>0,
$$

which specifies the probability that agent $i$ is assigned task $h$. Then, the task-specific equilibrium efforts are $e^{x}(\theta)=t_{x} \theta, x \in\{h, l\}$, and the expected equilibrium team output is

$$
\begin{aligned}
Y\left(\theta_{i}, \theta_{j}\right)= & f\left(\theta_{i}, \theta_{j}\right) z\left(\theta_{i}, \theta_{j}, e_{i}^{h}\left(\theta_{i}\right), e_{j}^{l}\left(\theta_{j}\right)\right) \\
& +\left(1-f\left(\theta_{i}, \theta_{j}\right)\right) z\left(\theta_{j}, \theta_{i}, e_{j}^{h}\left(\theta_{j}\right), e_{i}^{l}\left(\theta_{i}\right)\right) \\
= & \frac{f\left(\theta_{i}, \theta_{j}\right)\left(\theta_{i}^{2}-\theta_{j}^{2}\right)\left(t_{h}^{2}-t_{l}^{2}\right)+\theta_{j}^{2} t_{h}^{2}+\theta_{i}^{2} t_{l}^{2}}{2} \\
= & \frac{t_{h}^{2}\left(\theta_{i}^{r+2}+\theta_{j}^{r+2}\right)+t_{l}^{2}\left(\theta_{j}^{2} \theta_{i}^{r}+\theta_{i}^{2} \theta_{j}^{r}\right)}{2\left(\theta_{i}^{r}+\theta_{j}^{r}\right)} .
\end{aligned}
$$

Figure 2 shows the isoquants under the different selection precisions $r$. As in the exclusive leadership case (see Figure 1), low precision $r=.25$ is shown on the left, moderate precision $r=2$ in the middle, and high precision $r=15$ on the right. The task values are $t_{h}=2 / 3, t_{l}=1 / 3$.

The figure illustrates that under task matching and for a given pair $\left(t_{h}, t_{l}\right)$, the Apollo effect only crops up in cases where the subsequent selection precision $r$ is below the minimal threshold, which, in the present example, is implicitly given by

$$
\frac{2 \theta_{2}^{2}\left(\theta_{1}^{r}+\theta_{2}^{r}\right)}{\left(\theta_{1}^{2}-\theta_{2}^{2}\right)\left(\theta_{1} \theta_{2}\right)^{r}}=r \frac{t_{h}^{2}-t_{l}^{2}}{\theta_{1}^{r} t_{h}^{2}+\theta_{2}^{r} t_{l}^{2}}
$$



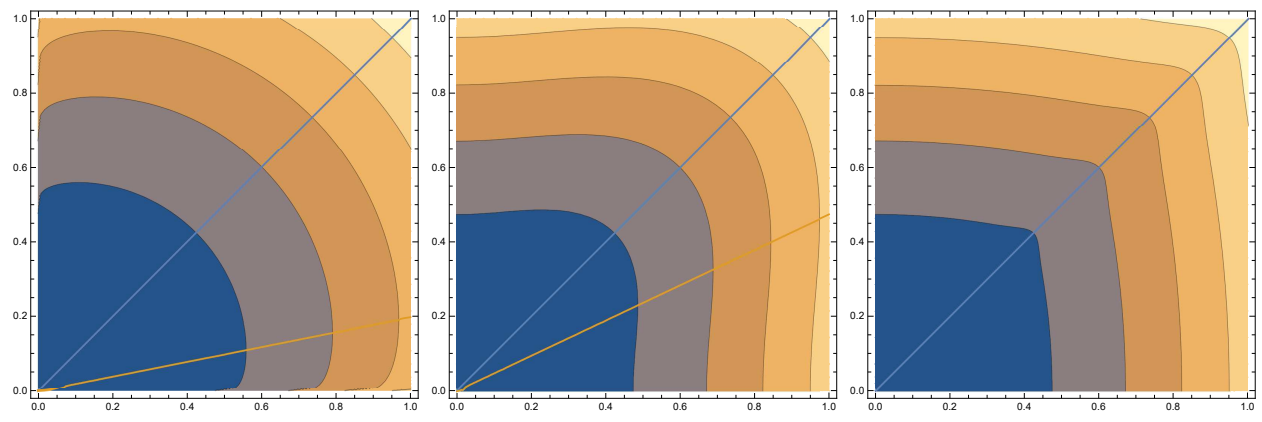

Figure 2: Task-matching level sets showing expected output for $t_{h}=2 / 3$ and $t_{l}=1 / 3$. The level sets are drawn for $r=.25$ on the left, $r=2$ in the middle, and $r=15$ on the right. The solid golden line represents condition (26).

or, plugging in the example values, $r<3.3545$. This threshold condition expresses that the less it matters who is assigned to which task, i.e., the closer $t^{h}$ and $t^{l}$ are, the more likely it is that assignment mistakes must be made in order for the Apollo effect to arise. $\triangleleft$

Intuitively, we can decompose the second player's marginal output contribution into two components: productive and disruptive. For the moment, consider the (efficient) case of an infinitely precise allocation function $f$, where the disruptive effect does not arise. Starting at any interior point $\hat{\theta}=\theta_{1}=\theta_{2}$ on the diagonal in Figures 2, 3, and 4, a decrease in $\theta_{2}$ results in lower output and hence must be compensated by an increase in $\theta_{1}$ in order to stay on the same isoquant $I(\cdot)$. Hence, the isoquants in the middle panel of the top row of Figure 3 now become "triangular" in the sense that the point on the diagonal where $\theta_{1}=\theta_{2}=\hat{\theta}$ is connected by a negatively sloped curve with the point on the horizontal axis where $\left(\tilde{\theta}_{1}>\hat{\theta}_{1}, \theta_{2}=0\right)$. This latter point is to the right of the point $\left(\hat{\theta}_{1}, \theta_{2}=0\right)$ directly under the diagonal from which we started. The horizontal shift of the isoquant depicts the marginal productive influence of player 2, which we call the "productive effect" (which includes, generally speaking, the "synergies" created by teamwork).

The isoquant maps discussed above are illustrated in Figure 3, and their detailed decomposition into productive and disruptive marginal effects is shown in Figure 4. The latter figure displays the productive marginal effect (the negative vertical slope of the blue isoquant $\left.I\left(a^{\prime}, b^{\prime}\right)\right)$ and the total marginal effect (the vertical slope of the red isoquant $I\left(a^{\prime \prime}, b^{\prime \prime}\right)$ ) for the task-matching case of 
$t_{h}>t_{l}$ and intermediate selection precision $f$.
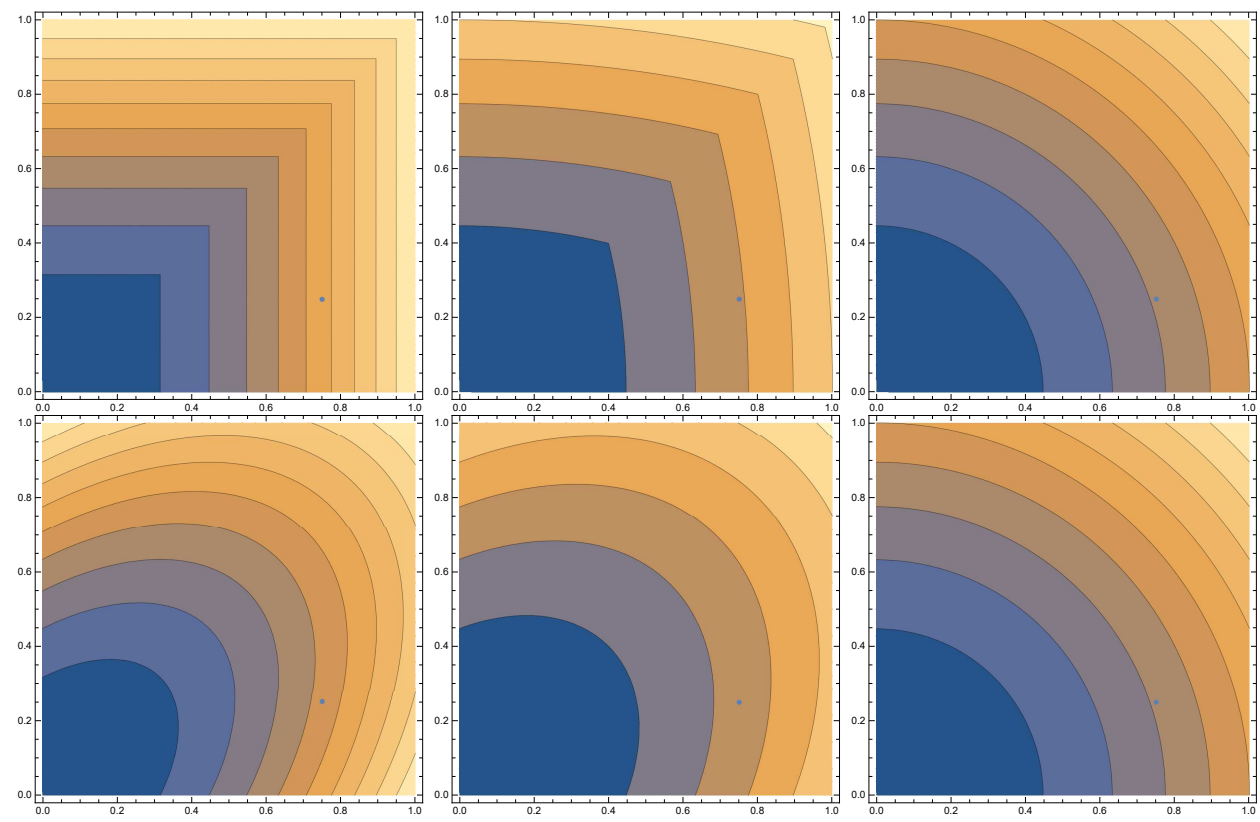

Figure 3: Isoquants for infinitely precise $f$ in the first row (illustrating the pure productive effect) and $r=1$ in the second row (illustrating both productive and disruptive effects). Plotted are the cases of $t_{h}=1$ and $t_{l}=0$ (left), $t_{l}=1 / 2$ (middle), and $t_{l}=1$ (right).

Any assignment function $f$ that satisfies our assumptions introduces allocative inefficiency, thereby shifting all points of the efficient-assignment blue isoquant - except for the two points on the diagonal and horizontal axis just pinned down - further to the right, resulting in the red isoquant of Figure 4. This is what we call the "disruptive effect." The disruptive effect tends to shift points $\left(\theta_{1}, \theta_{2}\right)$ close to the diagonal (where the chance of mistakes is highest) further to the right than those with lower $\theta_{2}$. But the Apollo effect arises only in the extreme case in which the disruptive effect causes an isoquant to become positively sloped. More precisely, it arises if the (negative) marginal disruptive effect - described by $f_{2}\left(\theta_{1}, \theta_{2}\right)$ —outweighs the (positive) marginal productive effect of a marginal increase of $\theta_{2}$.

Compare this to the exclusive leadership case considered in the previous section. There, as illustrated in the two left-hand panels of Figure 3 and the 

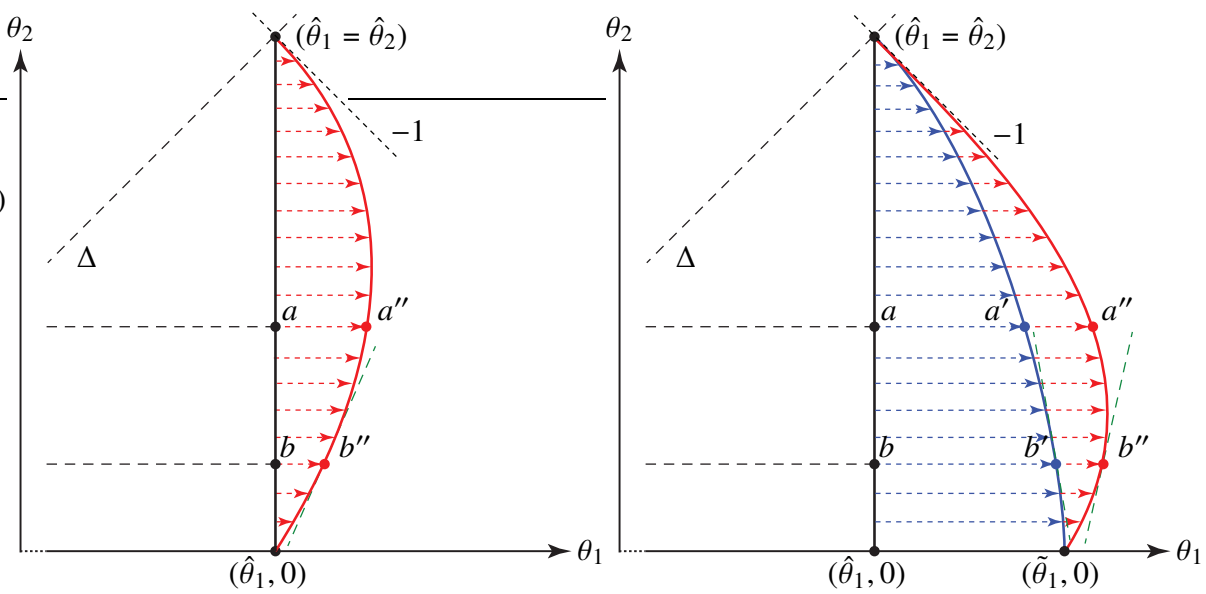

Figure 4: Three isoquants are shown on the right: infinitely precise $f: I(a, b)$ under exclusive leadership (black), infinitely precise $f: I\left(a^{\prime}, b^{\prime}\right)$ for task matching (blue), and finite $f: I\left(a^{\prime \prime}, b^{\prime \prime}\right)$ under task matching with $t_{h}>t_{l}$ (red). The marginal positively sloped (total) Apollo effect is represented by the dashed tangent through $b^{\prime \prime}$. The necessity of the Apollo effect under exclusive leadership for finite $f$ is illustrated on the left.

black isoquant of Figure 4, the efficient isoquant map is perfectly rectangular and any imprecision of $f$ leads to disruption. In particular, all points of the isoquant (except for those on the diagonal and horizontal axis) shift to the right. Hence, the Apollo effect is always present in the simpler exclusive leadership environment of Proposition 1. The existence of the Apollo effect in the task-matching environment of this section, however, depends on the marginal output of player 2 (1) - her productive contribution-being smaller than the disruptive effect introduced through the possibility of wrongly assigning her to the more (less) productive task $h(l)$. Our next result summarizes this intuition and generalizes the previous example by identifying a condition on the assignment function $f$ that guarantees that the Apollo effect arises also in the task-matching environment.

Proposition 2. For equilibrium task-matching production $z\left(\theta_{i}, \theta_{j}\right)$, a sufficient condition for the Apollo effect to arise for some type profile $\theta_{1}>\theta_{2}$ is that the 
selection technology $f\left(\theta_{1}, \theta_{2}\right)$ satisfies

$$
f_{2}\left(\theta_{1}, \theta_{2}\right)<\frac{z_{2}\left(\theta_{1}, \theta_{2}\right)+z_{1}\left(\theta_{2}, \theta_{1}\right)}{2 z\left(\theta_{2}, \theta_{1}\right)-2 z\left(\theta_{1}, \theta_{2}\right)} .
$$

Notice that the condition of this Proposition holds if $f_{2}\left(\theta_{1}, \theta_{2}\right)$ is sufficiently low (and negative). To get a better understanding of the last condition, observe that for $f$ infinitely precise, we have $f_{2}\left(\theta_{1}, \theta_{2}\right)=0$ for any $\theta_{1}>\theta_{2}$.

Example 3: We remain in the same environment as in the previous example with

$$
y\left(\theta_{i}, \theta_{j}, e_{i}, e_{j}\right)=t_{h} \theta_{i} e_{i}+t_{l} \theta_{j} e_{j}, \text { with } t_{h} \geq t_{l} .
$$

For quadratic costs and task-specific linear production (24), the equilibrium production is $y^{x}(\theta, e(\theta))=t_{x} \theta^{2}, x \in\{h, l\}$. The condition for an isoquant to have a positive slope (inequality (45) in the proof of Proposition 2) is

$$
\frac{t_{h}^{2}}{t_{h}^{2}-t_{l}^{2}}<f\left(\theta_{1}, \theta_{2}\right)-f_{2}\left(\theta_{1}, \theta_{2}\right) \frac{\theta_{1}^{2}-\theta_{2}^{2}}{2 \theta_{2}} .
$$

For the general ratio assignment function (7), this condition (28) equals

$$
\frac{t_{h}^{2}}{t_{h}^{2}-t_{l}^{2}}<\frac{\theta_{1}^{r}}{\theta_{1}^{r}+\theta_{2}^{r}}-\left(r \theta_{2}^{r-2}\right) \frac{\theta_{1}^{r}\left(\theta_{2}^{2}-\theta_{1}^{2}\right)}{2\left(\theta_{1}^{r}+\theta_{2}^{r}\right)^{2}},
$$

where the term $r \theta_{2}^{r-2}$ goes to infinity as $\theta_{2} \rightarrow 0$ for $0<r<2$, irrespective of $\theta_{1}>\theta_{2}$. Hence the claimed inequality holds for some spread of types. This is confirmed by the sufficient condition (27) which equals in this example

$$
-\frac{r \theta_{1}^{r} \theta_{2}^{r-1}}{\left(\theta_{1}^{r}+\theta_{2}^{r}\right)^{2}}<-\frac{\theta_{2}\left(t_{h}^{2}+t_{l}^{2}\right)}{\left(\theta_{1}^{2}-\theta_{2}^{2}\right)\left(t_{h}^{2}-t_{l}^{2}\right)} .
$$

At the arbitrary point $\theta_{1}=3 / 4, \theta_{2}=1 / 4$ (indicated in the below figure) and task multipliers $t_{h}=1, t_{l}=1 / 4$, this condition amounts to

$$
-\frac{r}{\cosh (r \log (3) / 2)^{2}}<-\frac{17}{30} \Leftrightarrow r \in[0.64,2.5] \text {. }
$$

Figure 5 shows examples of the corresponding output contour sets for different task multipliers and selection precisions. $\triangleleft$ 

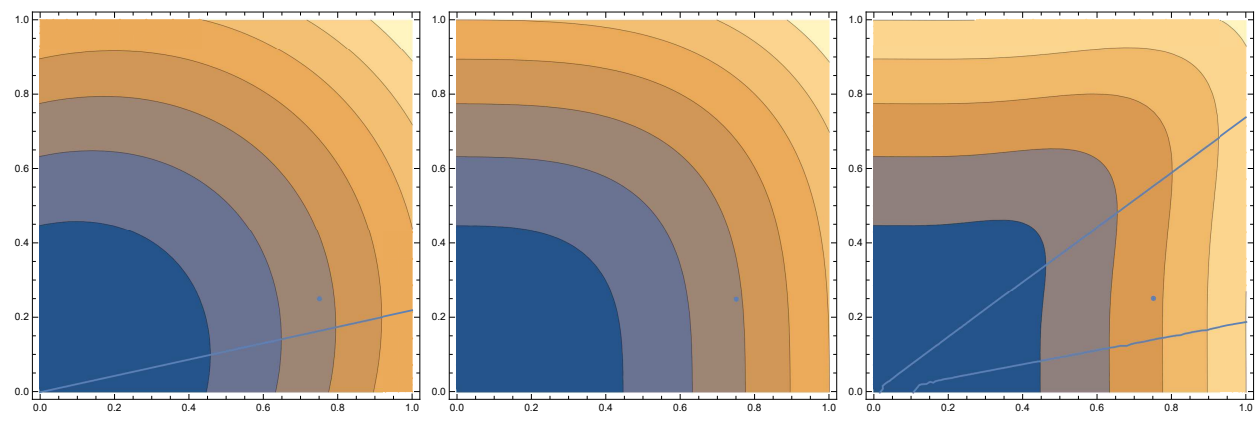

Figure 5: Left and center: type combinations for $t_{h}=1, t_{l}=3 / 4$ producing the same output $Y\left(\theta_{1}, \theta_{2}\right)$. The left panel shows the case of $r=1$, and the center panel showns the same isoquants for $r=2$. The blue lines show type-pairs for which the isoquants are vertical. The right panel illustrates a case of multiple critical locations $\left(t_{h}=1, t_{l}=1 / 4\right.$, and $\left.r=4\right)$.

Remark 8 (Black box assignment). There are many alternative interpretations of the black box assignment function $f$ that differ from the "mistakes" employed for both our leadership and task matching stories of this and the previous sections. The following example illustrates that the Apollo phenomenon may be alternatively explained by "lost complementarities" in production akin to elements of Belbin's motivation quoted in the Introduction. That is, the production function exploits heterogeneity in the skills of the team members. These benefits diminish as team members become more similar.

Example 4: ("Lost complementarities"). We simplify the task matching envi$\overline{\text { ronment to }} t_{l}=t_{h}=1$ and define output as

$$
\check{y}\left(\theta_{1}, \theta_{2}, e_{1}, e_{2}\right)=\theta_{1} e_{1}+\theta_{2} e_{2}-g\left(\theta_{1}, \theta_{2}\right) \phi,
$$

in which the "lost complementarities" are constant $\phi$, costs $c\left(e_{i}\right)$ are quadratic, and the "damage" function is

$$
g\left(\theta_{1}, \theta_{2}\right)=\frac{1-\left(\theta_{1}-\theta_{2}\right)^{2 r}}{2} .
$$

Notice that the function $\check{y}\left(\theta_{1}, \theta_{2}, e_{1}, e_{2}\right)$ satisfies all requirements to exhibit the Apollo effect. Given unchanged equilibrium efforts, $e^{*}\left(\theta_{i}\right)=\theta_{i} / 2$, the example of reference team $\theta^{A}=(.9, .1)$ is illustrated in Figure 6 that shows strictly inferior output for Apollo teams $\left(\theta_{2}^{A}=0.9, \tilde{\theta}_{2}\right)$ with $\tilde{\theta}_{2} \in(0.1,0.5)>\theta_{2}^{A} \cdot \triangleleft$ 


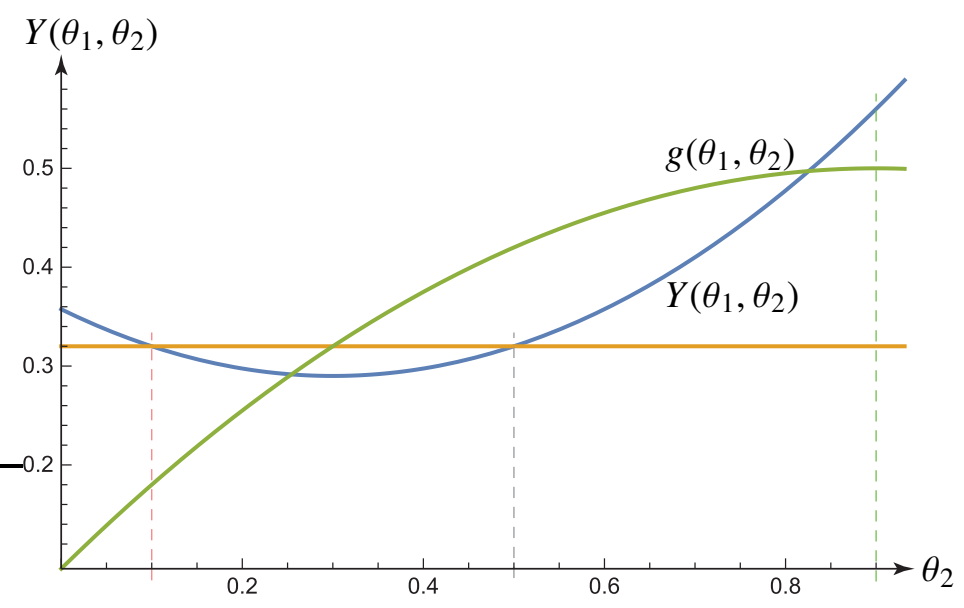

Figure 6: Lost complementarities example for $r=1$ and $\phi=1 / 2$. The blue curve is Apollo team output which is below the gold reference output of team $\theta^{A}=(.9, .1)$ for $\theta_{2} \in(.1, .5)$. The green curve shows the "assignment" function $g\left(\theta_{1}, \theta_{2}\right)$ defined in (33).

\subsection{Incomplete Information Among Agents}

In this section we illustrate the robustness of our previous results by relaxing the assumption that agents know each other's types. To do so, we assume that the types distribute independently and identically according to distribution function $G$ with density $g$ on support $[a, b]$. When exerting effort, each agent knows only his own type and whether or not (s)he was assigned as a leader. Therefore, a symmetric equilibrium is characterized by two functions: $e^{L}(\theta)$, the effort function of the agent who was selected to be the team leader, and $e^{F}(\theta)$, the effort function of the agent who was not selected to be the team leader.

Proposition 3. A pair of necessary conditions for agent equilibrium effort under incomplete information about agents' skills is

$\int_{a}^{b} y_{2}\left(\theta, e^{L}(\theta), e^{F}\left(\theta^{\prime}\right)\right) f\left(\theta, \theta^{\prime}\right) g\left(\theta^{\prime}\right) d \theta^{\prime}=2 c^{\prime}\left(e^{L}(\theta)\right) \int_{a}^{b} f\left(\theta, \theta^{\prime}\right) g\left(\theta^{\prime}\right) d \theta^{\prime}$ 
and

$$
\begin{aligned}
& \int_{a}^{b} y_{3}\left(\theta^{\prime}, e^{L}\left(\theta^{\prime}\right), e^{F}(\theta)\right) f\left(\theta^{\prime}, \theta\right) g\left(\theta^{\prime}\right) d \theta^{\prime} \\
& =2 c^{\prime}\left(e^{F}(\theta)\right) \int_{a}^{b} f\left(\theta^{\prime}, \theta\right) g\left(\theta^{\prime}\right) d \theta^{\prime}
\end{aligned}
$$

We illustrate this result for the same environment as in the previous examples. Assume that $c(e)=e^{2} / 2$ and $y\left(\theta, e_{1}, e_{2}\right)=\theta\left(e_{1}+e_{2}\right)$; then first-order conditions (34) and (35) become

$$
\begin{aligned}
e^{L}(\theta) & =\theta / 2, \\
e^{F}(\theta) & =\frac{\int_{a}^{b} \theta^{\prime} f\left(\theta^{\prime}, \theta\right) g\left(\theta^{\prime}\right) d \theta^{\prime}}{2 \int_{a}^{b} f\left(\theta^{\prime}, \theta\right) g\left(\theta^{\prime}\right) d \theta^{\prime}}=\mathbb{E}_{\theta^{\prime} \mid \text { follower has type } \theta\left[\theta^{\prime}\right]} \\
& =\frac{r+1}{2(r+2)} \frac{{ }_{2} F_{1}\left(1, \frac{r+2}{r} ; 2+\frac{2}{r} ;-\theta^{-r}\right)}{{ }_{2} F_{1}\left(1,1+\frac{1}{r} ; 2+\frac{1}{r} ;-\theta^{-r}\right)},
\end{aligned}
$$

where ${ }_{2} F_{1}(x)$ is the ordinary hypergeometric function (representing the hypergeometric series). ${ }^{18}$ Figure 7 gives an example of the uniform distribution. These equilibrium efforts yield expected team output

$$
\begin{aligned}
Y\left(\theta_{1}, \theta_{2}\right)= & f\left(\theta_{1}, \theta_{2}\right) y\left(\theta_{1}, e^{L}\left(\theta_{1}\right), e^{F}\left(\theta_{2}\right)\right) \\
& +\left(1-f\left(\theta_{1}, \theta_{2}\right)\right) y\left(\theta_{2}, e^{F}\left(\theta_{1}\right), e^{L}\left(\theta_{2}\right)\right) .
\end{aligned}
$$

Figure 7 shows isoquants for precisions $r \in\{0.25,2,8\}$. As the positively sloped parts of the isoquants illustrate, the Apollo effect is present in this example with incomplete information as well.

\subsection{Principal-Agent Model}

Contrary to the team production environment used for all other results of this paper, in this section we explore the robustness of our findings to the presence

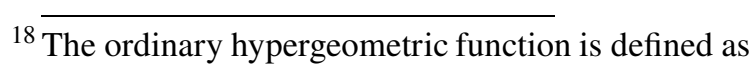

$$
{ }_{2} F_{1}(a, b ; c ; z)=\sum_{n=0}^{\infty} \frac{(a)_{n}(b)_{n}}{(c)_{n}} \frac{z^{n}}{n !} .
$$



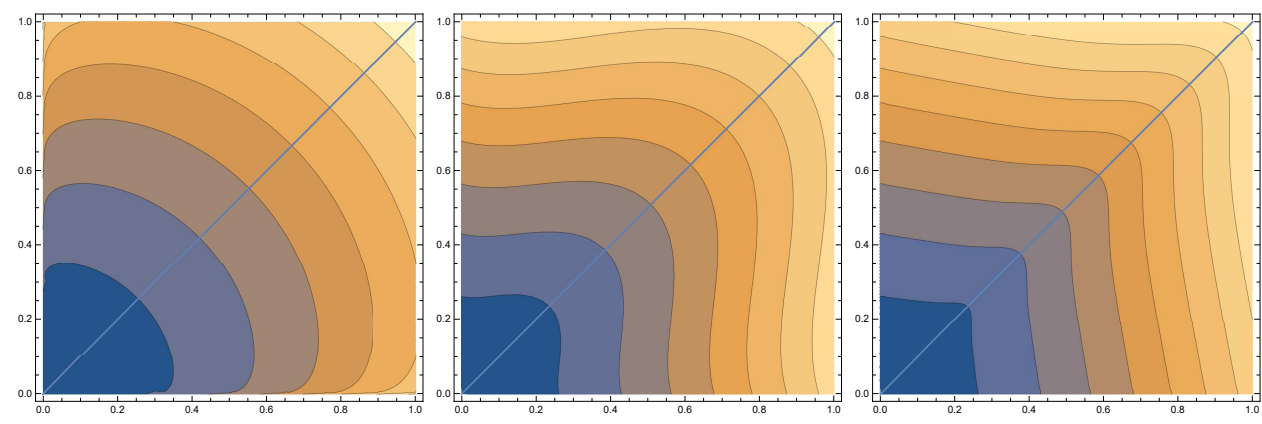

Figure 7: Expected team output level sets for uniformly distributed partner types for $r=.25$ on the left, $r=2$ in the middle, and $r=8$ on the right.

of a profit-maximizing principal who may act as a budget breaker and can therefore discipline the team members engaged in production. While we assume that the agents' efforts remain unobservable, we assume that final output is observable and contractible. Moreover, we assume that the principalalthough she does not observe the attributes of the chosen leader-knows the skill composition in the team. Therefore, the contract that the principal specifies may depend on the produced output and the composition of the leadership skills in the team (but not on the skills of the assigned leader).

We analyze the same production setup as before in an environment in which a board (the principal) appoints a manager to a team of heterogeneous agents. We model the situation in which this principal may make mistakes in assigning the "correct" leader to the team by assuming that the principal observes ranking information only on agent types' $\theta$, summarized by function $f$ in (7).

Example 5: In the exclusive production environment, assume that the principal pays a fixed wage ${ }^{19} w$ and that agents' efforts are observable by the principal (but types are not), and that wages can be conditioned on these efforts. Finally, we assume the same linear production function (8) as in the previous examples.

19 A similar example for the principal-agent model under task matching exhibits qualitatively comparable effects and is available from the authors. 
Then the principal and agents solve the problem

$$
\begin{aligned}
\max _{w(e)} & y=f\left[\theta_{1}\left(2 e_{i}^{1}\right)-2 w\left(e_{i}^{1}\right)\right]+(1-f)\left[\theta_{2}\left(2 e_{i}^{2}\right)-w\left(e_{i}^{2}\right)\right] \\
\text { s.t. } & u_{i}^{j}=w\left(e_{i}^{j}\right)-c\left(e_{i}^{j}\right) \geq 0 .
\end{aligned}
$$

Under standard quadratic costs, this is solved by

$$
e_{i}^{j}\left(\theta_{j}\right)=\theta_{j}, w\left(e_{i}^{j}\right)=\frac{\left(\theta^{j}\right)^{2}}{2} .
$$

Since efforts can be observed by the principal, (s)he can ex-post invert the observed efforts to learn the agents' types. However, this information is not available to her at the ex-ante stage when she makes the leadership assignment. Taking into account the assumed ratio-assignment mistakes (7), the expected equilibrium team output is

$$
2 \frac{\theta_{1}^{r+2}+\theta_{1}^{r+2}}{\theta_{1}^{r}+\theta_{2}^{r}}
$$

Our usual example confirms the possibility of the Apollo effect in this environment. Figure 8 shows that the principal's equilibrium profit exhibits the Apollo effect in all cases (the team output would show the same effect).
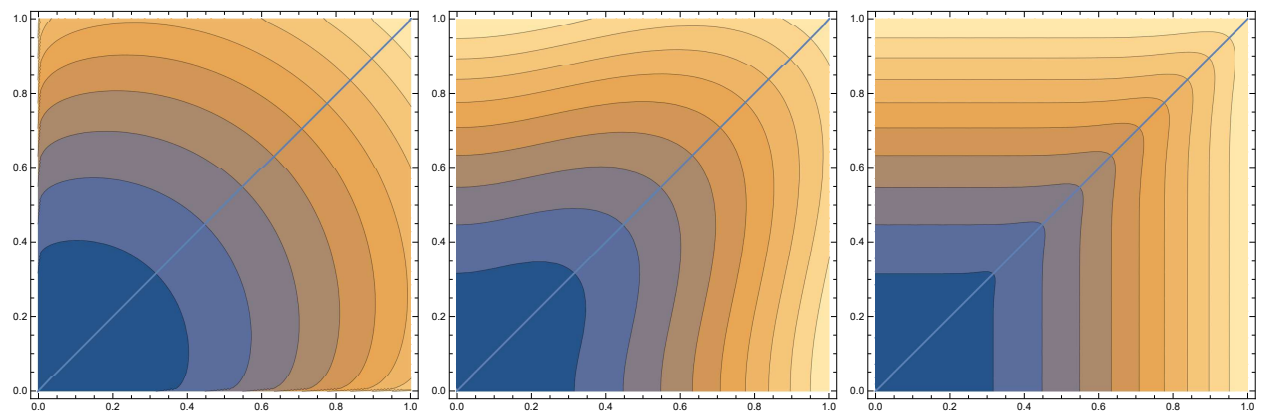

Figure 8: Expected profits in the principal-agent environment with observable efforts. The panels show selection precisions $r \in\{1 / 4,2,15\}$ from left to right.

We proceed to the case of unobservable efforts. We stay in the linear production environment with $y=\theta\left(e_{1}+e_{2}\right)$, quadratic costs $c(e)=e^{2} / 2$, and only two possible assignments: $\theta_{1}>\theta_{2}$. The principal sets the wage $w$ based 
on the observed output $y$. Without loss of generality we can assume that the principal pays equal amounts to both agents. The principal wants to induce effort of $e\left(\theta_{1}\right)$ when the assignment is $\theta_{1}$, and $e\left(\theta_{2}\right)$ when the assignment is $\theta_{2}$. Therefore, along the equilibrium path, the principal expects to see either $y\left(\theta_{1}\right)=2 \theta_{1} e\left(\theta_{1}\right)$ or $y\left(\theta_{2}\right)=2 \theta_{2} e\left(\theta_{2}\right)$. Without loss of generality we can assume that there are two wage levels: $w\left(y\left(\theta_{1}\right)\right)$ and $w\left(y\left(\theta_{2}\right)\right)$; for any other output, the principal pays a wage of zero.

Hence, the joint problem of the principal and the two agents is ${ }^{20}$

$$
\begin{aligned}
\underset{e(\theta), w(y(\theta))}{\max } & f\left[y\left(\theta_{1}\right)-2 w\left(y\left(\theta_{1}\right)\right)\right]+(1-f)\left[y\left(\theta_{2}\right)-2 w\left(y\left(\theta_{2}\right)\right)\right] \\
\text { s.t. } & \left(\mathrm{IR}_{1}\right): w\left(y\left(\theta_{1}\right)\right)-c\left(e\left(\theta_{1}\right)\right) \geq 0, \\
& \left(\mathrm{IR}_{2}\right): w\left(y\left(\theta_{2}\right)\right)-c\left(e\left(\theta_{2}\right)\right) \geq 0, \\
& \left(\mathrm{IC}_{1}\right): w\left(y\left(\theta_{1}\right)\right)-c\left(e\left(\theta_{1}\right)\right) \geq w\left(y\left(\theta_{2}\right)\right)-c\left(\frac{y\left(\theta_{2}\right)}{\theta_{1}}-\frac{y\left(\theta_{1}\right)}{2 \theta_{1}}\right), \\
& \left(\mathrm{IC}_{2}\right): w\left(y\left(\theta_{2}\right)\right)-c\left(e\left(\theta_{2}\right)\right) \geq w\left(y\left(\theta_{1}\right)\right)-c\left(\frac{y\left(\theta_{1}\right)}{\theta_{2}}-\frac{y\left(\theta_{2}\right)}{2 \theta_{2}}\right) .
\end{aligned}
$$

The wages (60) and the efforts (61) that solve this problem are derived in the appendix. We insert them into the principal's problem and plot the level sets of the principal's expected profit in Figure 9 for different precision levels of the assignment function $f$. As isoprofit curves have positive slopes for some type profiles in all cases, we confirm the Apollo effect also in the principal-agent environment. $\triangleleft$

${ }^{20}$ Switching into the standard principal-agent model of i.i.d. types in which $\lambda=\operatorname{Pr}\left(\theta_{1}\right)$ and $1-\lambda=\operatorname{Pr}\left(\theta_{2}\right)$ changes the principal's objective to

$$
\begin{aligned}
& \max _{e(\theta), w(y(\theta))} 2 \lambda(1-\lambda)\left(f\left[y\left(\theta_{1}\right)-2 w\left(y\left(\theta_{1}\right)\right)\right]+(1-f)\left[y\left(\theta_{2}\right)-2 w\left(y\left(\theta_{2}\right)\right)\right]\right) \\
& +\lambda^{2}\left(y\left(\theta_{1}\right)-2 w\left(y\left(\theta_{1}\right)\right)\right)+(1-\lambda)^{2}\left(y\left(\theta_{2}\right)-2 w\left(y\left(\theta_{2}\right)\right)\right)
\end{aligned}
$$

in which the principal's assignment capability $f$ only matters if non-constant agent typeprofiles become realized (which happens with probability $2 \lambda(1-\lambda)$ ). In the other two cases which happen with probability $\lambda^{2}$ and $(1-\lambda)^{2}$, respectively, the two types competing for leadership are identical. Note that this change leaves the constraints in (43) and therefore agent behavior qualitatively unaffected. Similar but weaker Apollo effects can be observed in such an extended model. 

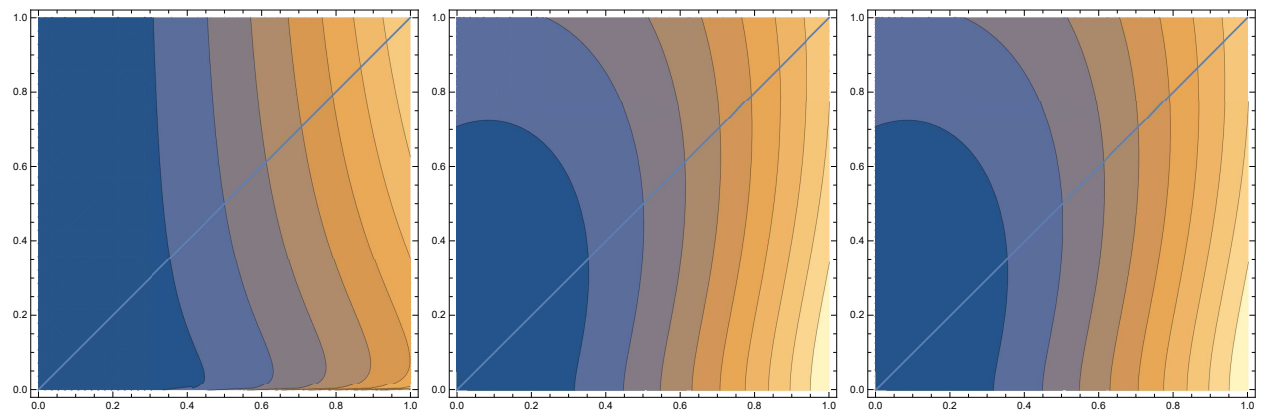

Figure 9: Expected PAM-profits for unobservable efforts that exhibit the Apollo effect. The level sets are drawn for $r \in\{0.25,2,15\}$; only region $\theta_{1}>\theta_{2}$ below the diagonal is relevant.

\subsection{Simulated Incidence}

How much of a problem is the Apollo effect? Because they strive to hire the brightest graduates, by definition, successful law firms, medical or accounting partnerships, etc, are all Apollo teams consisting of competitive individuals whose professional training may not always have emphasized lateral relationship skills. On average, the "real" Apollo teams documented by Belbin (referenced in footnote 1 ) ranked $4.6^{\text {th }}$ out of 6 . Our paper confirms that a theoretical basis for the Apollo effect exists but-anecdotal evidence notwithstanding - we cannot say much about how often it occurs in reality.

Hence, the purpose of this section is to present simulation results which may serve as a partial answer to this question. Our most stringent test of Apollo-plausibility is shown in Figure 7. There, we normalize $\theta_{1}^{A}=1$ and randomly draw $\theta_{2}^{A}$. Then, for each such pair, we randomly draw $\theta_{1}^{B}$ from $\left[0, \theta_{1}^{A}\right]$ and $\theta_{2}^{B}$ from $\left[0, \theta_{2}^{A}\right]$. This is done 100,000 times for each precision- $r$-step of $1 / 8$ for $r \in[0,5]$. In the case of exclusive leadership (Example 1) shown on the left, the Apollo effect occurs at most in 3\% of these random draws and is highest at a precision of $r \approx 9 / 8$. In the task-matching environment (Example 2) shown on the right, the Apollo effect occurs at most in $1.2 \%$ of the draws and is highest at a precision of $r \approx 6 / 8$. In both scenarios, therefore, the Apollo effect will usually be considered a surprise.

If more is known about the team composition-in particular about the high types-then more precise questions are possible. We now consider 

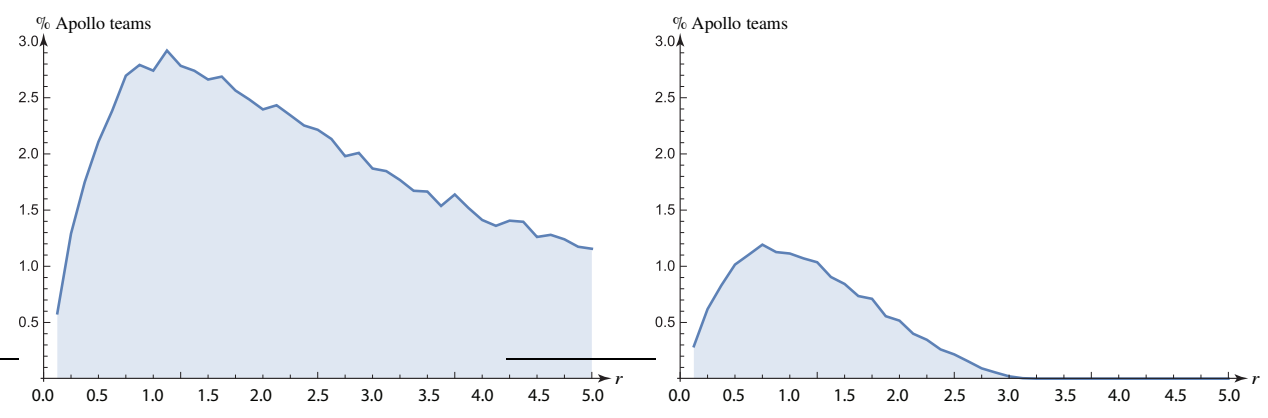

Figure 10: Simulated incidence of the Apollo effect for the exclusive leadership case (Example 1) on the left and task-matching (Example 2) on the right as a function of the selection precision $r$.

Apollo teams $\theta^{A}=\left(1, \theta_{2}^{B}\right)$, set $\theta_{1}^{B}=0.95$ and uniformly drew one hundred thousand partners $\theta_{2}^{B} \in\left[0, \theta_{2}^{A}\right]$. The percentage at which the Apollo effect (here loosely redefined as an underdog team $\theta^{B}$ producing higher output than the reference team $\theta^{A}$ ) occurs is shown for a range of selection precisions $r \in\{1 / 4,1 / 2,1,2,3,4\}$. The results are presented in Figure 11 for exclusive leadership (Example 1) on the left and task-matching (Example 2) on the right. In both cases, team $\mathrm{A}$ is composed of $\theta_{1}^{A}=1$, $\theta_{2}^{A} \in\left\{\frac{1}{10}, \frac{2}{10}, \frac{3}{10}, \frac{4}{10}, \frac{5}{10}, \frac{6}{10}, \frac{7}{10}, \frac{8}{10}, \frac{9}{10}, 1\right\}$, team B is $\theta_{1}^{A}=0.95$, together with 100,000 uniformly drawn $\theta_{2}^{B} \sim U_{\left[0, \theta_{2}^{A}\right]}$.
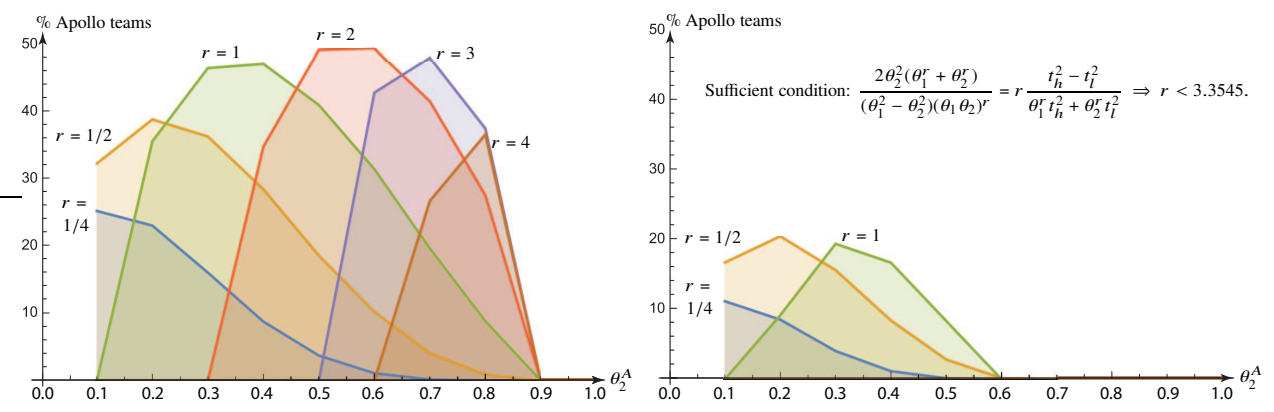

Figure 11: Simulated incidence of Apollo effect: Exclusive leadership (Example 1) on the left and task-matching (Example 2) on the right.

Whether these simulations bear any interesting correlation with what hapJournal of Mechanism and Institution Design 6(1), 2021 
pens in "real life" depends, of course, on the assumptions we made in Examples 1 and 2, and the chosen simulation parameters. If the observations reported by Belbin (1981) are taken as a yardstick, however, these seem conservative.

\section{CONCLUDING REMARKS}

Successful law firms, medical or accounting partnerships, etc. strive to hire the brightest graduates for their organizations. By definition, these firms are Apollo teams, consisting of competitive individuals whose professional training may not always have emphasized lateral relationship skills. This paper provides a model for systematically thinking about the implications of this observation.

At its core, the present paper analyzes the influence of the available skill profile on team production in the presence of promotion or other task assignment decisions. To do so, we model team members' skills as exogenous and let an official who has only statistical information on the workers' skills match the team members to tasks or positions. The baseline analysis shows that mistakes of this kind inevitably lead to what is called the Apollo effect: the property that teams composed of weaker individuals may outperform teams of unambiguously higher-qualified individuals in terms of team output. Our model's extensions allow for more complex task assignment or production modes, private information concerning the skills of the workers, and the presence of a profit-maximizing principal. We show that in all cases, to some extent, the Apollo effect cannot be avoided.

Many other economically interesting situations can be modeled with the methodology developed in this paper. For instance, a standard electoral competition model could be enriched through politicians choosing platforms (their "types" in our model) and voters who are unable to perfectly discriminate between these platforms may make mistakes in choosing their candidates. This would presumably counteract the tendency of candidates to move toward the median as such a convergence would maximize the probability of mistakes by the electorate. Another application of a similar idea is the possibility of making mistakes when identifying the "best" bid in general auction environments when (potentially multi-dimensional) bids are close.

This paper presents an analytically rigorous way of generating the Apollo effect in a variety of production environments. The resulting way of thinking about organizations has, in our view, important implications. Effects similar 
to those we report for leadership selection are at work for imperfect project selection with unobserved quality and training investments in human capital. Looking beyond the production environment, it can be seen that selecting a speaker from competing party officials, choosing the most promising of several architectural designs, or picking a substitute goalkeeper from sets of alternatives in a soccer team may all give rise to similarly negative effects in terms of expected overall performance. ${ }^{21}$

\section{Appendix}

Proof of Lemma 2. We show that while $\partial Y\left(\theta_{1}, \theta_{2}\right) / \partial \theta_{1}>0$ always holds, it is the case that $\partial Y\left(\theta_{1}, \theta_{2}\right) / \partial \theta_{2}<0$ if and only if the condition of the lemma holds. In this latter case, there exist $\left(\eta_{1}, \eta_{2}\right)>>0$ such that (14) holds. Taking the derivative of (13) with respect to $\theta_{2}$ gives the change in output for an increase in type $\theta_{2}$ as

$$
\begin{aligned}
& f_{2}\left(\theta_{1}, \theta_{2}\right)\left(y\left(\theta_{1}, e^{*}\left(\theta_{1}\right), e^{*}\left(\theta_{1}\right)\right)-y\left(\theta_{2}, e^{*}\left(\theta_{2}\right), e^{*}\left(\theta_{2}\right)\right)\right) \\
& +\left(1-f\left(\theta_{1}, \theta_{2}\right)\right)\left(e ^ { \prime * } ( \theta _ { 2 } ) \left(y_{3}\left(\theta_{2}, e^{*}\left(\theta_{2}\right), e^{*}\left(\theta_{2}\right)\right)\right.\right. \\
& \left.\left.+y_{2}\left(\theta_{2}, e^{*}\left(\theta_{2}\right), e^{*}\left(\theta_{2}\right)\right)\right)+y_{1}\left(\theta_{2}, e^{*}\left(\theta_{2}\right), e^{*}\left(\theta_{2}\right)\right)\right),
\end{aligned}
$$

where $y_{e}\left(\theta_{2}, e^{*}\left(\theta_{2}\right), e^{*}\left(\theta_{2}\right)\right)=y_{2}\left(\theta_{2}, e^{*}\left(\theta_{2}\right), e^{*}\left(\theta_{2}\right)\right)=y_{3}\left(\theta_{2}, e^{*}\left(\theta_{2}\right), e^{*}\left(\theta_{2}\right)\right)$. This change is negative if (15) holds. As claimed, the derivative of $Y\left(\theta_{1}, \theta_{2}\right)$ with respect to $\theta_{1}$ is

$$
\begin{aligned}
& f_{1}\left(\theta_{1}, \theta_{2}\right)\left[y\left(\theta_{1}, e^{*}\left(\theta_{1}\right), e^{*}\left(\theta_{1}\right)\right)-y\left(\theta_{2}, e^{*}\left(\theta_{2}\right), e^{*}\left(\theta_{2}\right)\right)\right] \\
& +f\left(\theta_{1}, \theta_{2}\right)\left[e^{* *}\left(\theta_{1}\right) 2 y_{e}\left(\theta_{1}, e^{*}\left(\theta_{1}\right), e^{*}\left(\theta_{1}\right)\right)+y_{1}\left(\theta_{1}, e^{*}\left(\theta_{1}\right), e^{*}\left(\theta_{1}\right)\right)\right]>0 .
\end{aligned}
$$

Proof of Lemma 3. By assumption of symmetry and $f(0, \hat{\theta})=0$.

Proof of Proposition 1. From Lemmata 1 and 2 and the intermediate value theorem, every feasible continuous function $f$ has a range in which the slope of the isoquant is positive.

${ }^{21}$ See Woolley et al. (2015) for a particularly interesting example of the performance of the Russian (Apollo) ice hockey team at the 2014 Sochi olympics. For an account of other recent dream team failures, see Martinez (2013). 
Proof of Proposition 2. The condition for the isoquant to have positive slope, i.e., for the derivative of output $Y\left(\theta_{1}, \theta_{2}\right)$ from (22) with respect to $\theta_{2}$ to be negative, is

$$
\frac{z_{1}\left(\theta_{2}, \theta_{1}\right)}{z_{1}\left(\theta_{2}, \theta_{1}\right)-z_{2}\left(\theta_{1}, \theta_{2}\right)}<f\left(\theta_{1}, \theta_{2}\right)-f_{2}\left(\theta_{1}, \theta_{2}\right) \frac{z\left(\theta_{1}, \theta_{2}\right)-z\left(\theta_{2}, \theta_{1}\right)}{z_{1}\left(\theta_{2}, \theta_{1}\right)-z_{2}\left(\theta_{1}, \theta_{2}\right)} .
$$

Assumptions (19) and (21) imply single-crossing of $z_{1}$ and $z_{2}$ since

$$
\begin{aligned}
z_{1}\left(\theta_{2}, \theta_{1}\right)-z_{2}\left(\theta_{1}, \theta_{2}\right) & =e_{1}^{h}\left(\theta_{2}\right) y_{2}^{h}\left(\theta_{2}, e^{h}\left(\theta_{2}\right)\right)-e_{1}^{l}\left(\theta_{2}\right) y_{2}^{l}\left(\theta_{2}, e^{l}\left(\theta_{2}\right)\right) \\
& +y_{1}^{h}\left(\theta_{2}, e^{h}\left(\theta_{2}\right)\right)-y_{1}^{l}\left(\theta_{2}, e^{l}\left(\theta_{2}\right)\right)>0,
\end{aligned}
$$

where the second line of the last expression is positive due to the assumption that $y_{1}^{h}(\theta, e)>y_{1}^{l}(\theta, e)>0$ and $e^{h}\left(\theta_{2}\right)>e^{l}\left(\theta_{2}\right)$. The first line is positive since $e^{h \prime}\left(\theta_{2}\right)>e^{l \prime}\left(\theta_{2}\right)$ and $y_{2}^{h}\left(\theta_{2}, e^{h}\left(\theta_{2}\right)\right)>y_{2}^{l}\left(\theta_{2}, e^{l}\left(\theta_{2}\right)\right)$, which, in turn, follows from

$$
y_{2}^{h}\left(\theta_{2}, e^{h}\left(\theta_{2}\right)\right)=2 c^{\prime}\left(e^{h}\left(\theta_{2}\right)\right) \text { and } y_{2}^{h}\left(\theta_{2}, e^{l}\left(\theta_{2}\right)\right)=2 c^{\prime}\left(e^{l}\left(\theta_{2}\right)\right),
$$

$e^{h}\left(\theta_{2}\right)>e^{l}\left(\theta_{2}\right)$, and $c^{\prime \prime}>0$. Thus, the left-hand side of (45) exceeds 1 while the term multiplied with $f_{2}\left(\theta_{1}, \theta_{2}\right)$ on the right-hand side of (45) is positive. Hence, as $f\left(\theta_{1}, \theta_{2}\right) \in[1 / 2,1]$, a sufficient condition for the Apollo effect to arise for some type profile $\theta_{1}>\theta_{2}$ is (27).

Proof of Proposition 3. Equilibrium effort functions must satisfy

$$
\begin{gathered}
e^{L}(\theta) \in \arg \max _{e} \mathbb{E}_{\theta^{\prime} \mid \text { leader has type } \theta}\left[\frac{y\left(\theta, e, e^{F}\left(\theta^{\prime}\right)\right)}{2}\right]-c(e), \\
e^{F}(\theta) \in \arg \max _{e} \mathbb{E}_{\theta^{\prime} \mid \text { follower has type } \theta}\left[\frac{y\left(\theta^{\prime}, e, e^{L}\left(\theta^{\prime}\right)\right)}{2}\right]-c(e) .
\end{gathered}
$$

We calculate the conditional expectations as

$$
\begin{aligned}
\operatorname{Pr}\left(\Theta \leq \theta^{\prime} \mid \text { leader has type } \theta\right) & =\frac{\operatorname{Pr}\left(\Theta \leq \theta^{\prime} \& \text { leader has type } \theta\right)}{\operatorname{Pr}(\text { leader has type } \theta)} \\
& =\quad \frac{\int_{a}^{\theta^{\prime}} f\left(\theta, \theta^{\prime \prime}\right) g\left(\theta^{\prime \prime}\right) d \theta^{\prime \prime}}{\int_{a}^{b} f\left(\theta, \theta^{\prime \prime}\right) g\left(\theta^{\prime \prime}\right) d \theta^{\prime \prime}} .
\end{aligned}
$$


Therefore, the density of ( $\theta^{\prime} \mid$ leader has type $\left.\theta\right)$ is

$$
\frac{f\left(\theta, \theta^{\prime}\right) g\left(\theta^{\prime}\right)}{\int_{a}^{b} f\left(\theta, \theta^{\prime \prime}\right) g\left(\theta^{\prime \prime}\right) d \theta^{\prime}} \text {. }
$$

Therefore,

$$
\mathbb{E}_{\theta^{\prime} \mid \text { leader has type } \theta} \frac{y\left(\theta, e, e^{F}\left(\theta^{\prime}\right)\right)}{2}=\frac{\int_{a}^{b} y\left(\theta, e, e^{F}\left(\theta^{\prime}\right)\right) f\left(\theta, \theta^{\prime}\right) g\left(\theta^{\prime}\right) d \theta^{\prime}}{2 \int_{a}^{b} f\left(\theta, \theta^{\prime \prime}\right) g\left(\theta^{\prime \prime}\right) d \theta^{\prime \prime}} .
$$

The first-order condition is given by

$$
\frac{\int_{a}^{b} y_{2}\left(\theta, e, e^{F}\left(\theta^{\prime}\right)\right) f\left(\theta, \theta^{\prime}\right) g\left(\theta^{\prime}\right) d \theta^{\prime}}{2 \int_{a}^{b} f\left(\theta, \theta^{\prime \prime}\right) g\left(\theta^{\prime \prime}\right) d \theta^{\prime \prime}}-c^{\prime}(e)=0 .
$$

Therefore, $e^{L}(\theta)$ must satisfy (34). Calculating the conditional expectations for the second case gives

$$
\begin{aligned}
\operatorname{Pr}\left(\Theta \leq \theta^{\prime} \mid \text { follower has type } \theta\right) & =\frac{\operatorname{Pr}\left(\Theta \leq \theta^{\prime} \& \text { follower has type } \theta\right)}{\operatorname{Pr}(\text { follower has type } \theta)} \\
& =\frac{\int_{a}^{\theta^{\prime}} f\left(\theta^{\prime \prime}, \theta\right) g\left(\theta^{\prime \prime}\right) d \theta^{\prime \prime}}{\int_{a}^{b} f\left(\theta^{\prime \prime}, \theta\right) g\left(\theta^{\prime \prime}\right) d \theta^{\prime \prime}} \\
& =\frac{\int_{a}^{\theta^{\prime}}\left[1-f\left(\theta, \theta^{\prime \prime}\right)\right] g\left(\theta^{\prime \prime}\right) d \theta^{\prime \prime}}{\int_{a}^{b}\left[1-f\left(\theta, \theta^{\prime \prime}\right)\right] g\left(\theta^{\prime \prime}\right) d \theta^{\prime \prime}} .
\end{aligned}
$$

Therefore, the density of $\left(\theta^{\prime} \mid\right.$ follower has type $\left.\theta\right)$ is

$$
\frac{f\left(\theta^{\prime}, \theta\right) g\left(\theta^{\prime}\right) d \theta^{\prime}}{\int_{a}^{b} f\left(\theta^{\prime \prime}, \theta\right) g\left(\theta^{\prime \prime}\right) d \theta^{\prime \prime}}
$$

Therefore,

$$
\mathbb{E}_{\theta^{\prime} \mid \text { follower has type } \theta} \frac{y\left(\theta^{\prime}, e, e^{L}\left(\theta^{\prime}\right)\right)}{2}=\frac{\int_{a}^{b} y\left(\theta^{\prime}, e^{L}\left(\theta^{\prime}\right), e\right) f\left(\theta^{\prime}, \theta\right) g\left(\theta^{\prime}\right) d \theta^{\prime}}{2 \int_{a}^{b} f\left(\theta^{\prime \prime}, \theta\right) g\left(\theta^{\prime \prime}\right) d \theta^{\prime \prime}} .
$$


The first-order condition is given by

$$
\frac{\int_{a}^{b} y_{3}\left(\theta^{\prime}, e^{L}\left(\theta^{\prime}\right), e\right) f\left(\theta^{\prime}, \theta\right) g\left(\theta^{\prime}\right) d \theta^{\prime}}{2 \int_{a}^{b} f\left(\theta^{\prime}, \theta\right) g\left(\theta^{\prime}\right) d \theta^{\prime}}-c^{\prime}(e)=0 .
$$

Therefore, we know that $e^{F}(\theta)$ must satisfy (35).

\section{Derivation of equilibrium efforts and wages in Example 5.}

Assume that both $\left(\mathrm{IR}_{2}\right)$ and $\left(\mathrm{IC}_{1}\right)$ are binding. Combining $\left(\mathrm{IR}_{2}\right)$ and $\left(\mathrm{IC}_{1}\right)$ gives

$$
e\left(\theta_{2}\right)=\sqrt{2} \sqrt{w\left(y\left(\theta_{2}\right)\right)}, e\left(\theta_{1}\right)=\frac{\theta_{1}^{2}\left(w\left(y\left(\theta_{1}\right)\right)-w\left(y\left(\theta_{2}\right)\right)\right)+4 \theta_{2}^{2} w\left(y\left(\theta_{2}\right)\right)}{2 \sqrt{2} \theta_{1} \theta_{2} \sqrt{w\left(y\left(\theta_{2}\right)\right)}} .
$$

Inserting these into $\left(\mathrm{IR}_{1}\right)$ gives

$$
w\left(y\left(\theta_{1}\right)\right)=w\left(y\left(\theta_{2}\right)\right) \frac{\left(\theta_{1}+2 \theta_{2}\right)^{2}}{\theta_{1}^{2}} .
$$

Inserting this back into the principal's problem in (43) gives her the following unconstrained objective:

$$
2 \sqrt{w\left(y\left(\theta_{2}\right)\right)}\left(\sqrt{2} \theta_{2}+\frac{\left(\theta_{1}+\theta_{2}\right) \theta_{1}^{r-2}\left(\sqrt{2} \theta_{1}^{2}-4 \theta_{2} \sqrt{w\left(y\left(\theta_{2}\right)\right)}\right)}{\theta_{1}^{r}+\theta_{2}^{r}}-\sqrt{w\left(y\left(\theta_{2}\right)\right)}\right) .
$$

Taking the derivative with respect to $w_{2}=w\left(y\left(\theta_{2}\right)\right)$ and solving results in the pair of wages

$$
\begin{aligned}
& w\left(y\left(\theta_{1}\right)\right)=\frac{\theta_{1}^{2}\left(\theta_{1}+2 \theta_{2}\right)^{2}\left(\left(\theta_{1}+2 \theta_{2}\right) \theta_{1}^{r}+\theta_{2}^{r+1}\right)^{2}}{2\left(\left(\theta_{1}+2 \theta_{2}\right)^{2} \theta_{1}^{r}+\theta_{1}^{2} \theta_{2}^{r}\right)^{2}}, \\
& w\left(y\left(\theta_{2}\right)\right)=\frac{\theta_{1}^{4}\left(\left(\theta_{1}+2 \theta_{2}\right) \theta_{1}^{r}+\theta_{2}^{r+1}\right)^{2}}{2\left(\left(\theta_{1}+2 \theta_{2}\right)^{2} \theta_{1}^{r}+\theta_{1}^{2} \theta_{2}^{r}\right)^{2}}
\end{aligned}
$$


implying efforts of

$$
\begin{aligned}
& e\left(\theta_{1}\right)=\frac{\theta_{1}\left(\theta_{1}+2 \theta_{2}\right)\left(\left(\theta_{1}+2 \theta_{2}\right) \theta_{1}^{r}+\theta_{2}^{r+1}\right)}{\left(\theta_{1}+2 \theta_{2}\right)^{2} \theta_{1}^{r}+\theta_{1}^{2} \theta_{2}^{r}}, \\
& e\left(\theta_{2}\right)=\frac{\theta_{1}^{2}\left(\left(\theta_{1}+2 \theta_{2}\right) \theta_{1}^{r}+\theta_{2}^{r+1}\right)}{\left(\theta_{1}+2 \theta_{2}\right)^{2} \theta_{1}^{r}+\theta_{1}^{2} \theta_{2}^{r}}
\end{aligned}
$$

\section{References}

Andreoni, J. (2006). Leadership giving in charitable fund-raising. Journal of Public Economic Theory, 8(1), 1-22.

Aritzeta, A., Swailes, S., \& Senior, B. (2007). Belbin's team role model: Development, validity and applications for team building. Journal of Management Studies, 44(1), 96-118.

Bag, P., \& Pepito, N. (2012). Peer transparency in teams: Does it help or hinder incentives? International Economic Review, 53(4), 1257-86.

Belbin, R. M. (1981). Management Teams: Why They Succeed or Fail (3rd ed.). Oxford, UK: Butterworth-Heinemann.

Bolton, P., Brunnermeier, M., \& Veldkamp, L. (2010). Economists' perspectives on leadership. In N. Nohria \& R. Khurana (Eds.), Handbook of Leadership Theory and Practice (pp. 239-264). Boston, MA: Harvard Business Press.

Chade, H., \& Eeckhout, J. (2020). Competing teams. Review of Economic Studies, 87, 1134-73.

Che, Y.-K., \& Yoo, S.-W. (2001). Optimal incentives for teams. American Economic Review, 91(3), 525-41.

Cyert, R. M., \& March, J. G. (1963). A Behavioral Theory of the Firm (2nd ed.). Cambridge, MA: Blackwell Publishers.

Eliaz, K., \& Wu, Q. (2018). A simple model of competition between teams. Journal of Economic Theory, 176, 732-92.

Garicano, L., \& Van Zandt, T. (2012). Hierarchies and the division of labor. In R. Gibbons \& J. Roberts (Eds.), Handbook of Organizational Economics (pp. 60454). Princeton University Press.

Gary, L. (1998, April). Cognitive Bias: Systematic Errors in Decision Making. Harvard Management Update.

Gershkov, A., Li, J., \& Schweinzer, P. (2016). How to share it out: The value of information in teams. Journal of Economic Theory, 162, 261-304.

Gigerenzer, G., \& Gaissmaier, W. (2011). Heuristic decision making. Annual Review of Psychology, 62, 451-382. 
Hermalin, B. E. (1998). Toward an economic theory of leadership: Leading by example. American Economic Review, 88(5), 1188-206.

Hermalin, B. E. (2012). Leadership and corporate culture. In R. Gibbons \& J. Roberts (Eds.), Handbook of Organizational Economics (pp. 432-78). Princeton University Press.

Hermalin, B. E., \& Weisbach, M. S. (1988). The determinants of board composition. RAND Journal of Economics, 19(4), 589-606.

Holmström, B. (1977). On Incentives and Control in Organizations. Stanford University, PhD Thesis.

Huck, S., \& Rey-Biel, P. (2006). Endogenous leadership in teams. Journal of Institutional and Theoretical Economics, 162(2), 253-61.

Jia, H., Skaperdas, S., \& Vaidya, S. (2013). Contest functions: Theoretical foundations and issues in estimation. International Journal of Industrial Organization, 31, 211 22.

Kahneman, D. (2003). Maps of bounded rationality: Psychology for behavioral economics. American Economic Review, 93(5), 1449-75.

Kobayashi, H., \& Suehiro, H. (2005). Emergence of leadership in teams. Japanese Economic Review, 56(3), 295-316.

Kremer, I., Mansour, Y., \& Perry, M. (2014). Implementing the "wisdom of the crowd". Journal of Political Economy, 122(5), 988-1012.

Lazear, E. P. (2012). Leadership: A personnel economics approach. Labor Economics, 19(1), 92-101.

Lazear, E. P., \& Rosen, S. (1981). Rank order tournaments as optimal labor contracts. Journal of Political Economy, 89, 841-64.

Lombardi, R., Trequattrini, R., \& Battistan, M. (2014). Systematic errors in decision making processes: The case of the Italian Serie A football championship. International Journal of Applied Decision Sciences, 7, 239-54.

Marschak, J., \& Radner, R. (1972). Economic Theory of Teams. New Haven, CT: Yale University Press.

Martinez, J. (2013, 10-Apr). A recent history of failed dream teams. Complex. Retrieved from http://www.complex.com/sports/2013/04/ a-history-of-failed-dream-teams/

Mathieu, J., Tannenbaum, S., Donsbach, J., \& Alliger, G. (2013). A review and integration of team composition models: Moving toward a dynamic and temporal framework. Journal of Management, 40(1), 130-60.

McAfee, R. P. (2002). Coarse matching. Econometrica, 70(5), 2025-34.

Palomino, F., \& Sákovics, J. (2004). Inter-league competition for talent vs. competitive balance. International Journal of Industrial Organization, 22(6), 783-97.

Rajan, R. G., \& Zingales, L. (2000). The tyranny of inequality. Journal of Public 
Economics, 76(3), 521-58.

Schwenk, C. R. (1984). Cognitive simplification processes in strategic decision making. Strategic Management Journal, 5(2), 111-28.

Shellenbarger, S. $(2016,20-\mathrm{Dec})$. A manifesto to end boring meetings. The Wall Street Journal. Retrieved from http://www.wsj.com/articles/ a-manifesto-to-end-boring-meetings-1482249683

Tetlock, P. E. (2000). Cognitive biases and organizational correctives: Do both disease and cure depend on the politics of the beholder? Administrative Science Quarterly, 45, 293-326.

Tirole, J. (2006). The Theory of Corporate Finance. Princeton, New Jersey: Princeton University Press.

Waldman, M. (2012). Theory and evidence in internal labor markets. In R. Gibbons \& J. Roberts (Eds.), Handbook of Organizational Economics (pp. 520-74). Princeton University Press.

Winter, E. (2006). Optimal incentives for sequential production processes. RAND Journal of Economics, 37(2), 376-90.

Woolley, A. W., Aggarwal, I., \& Malone, T. W. (2015). Collective intelligence in teams and organizations. In T. W. Malone \& M. S. Bernstein (Eds.), Handbook of Collective Intelligence (pp. 143-168). Cambridge, MA: Massachusetts Institute of Technology Press. 